\title{
Converting Primary Resources Into Useful Energy: The Pollution Ceiling Efficiency Paradox *
}

\author{
Jean-Pierre Amigues ${ }^{\dagger}$ and Michel Moreaux ${ }^{\ddagger}$
}

December 13, 2018

*We thank the participants of the EAERE Helsinki 2015 conference, especially Amos Zemel and Rüdiger Pethig, the participants of the Toulouse climate and energy conference, 2015, two anonymous referees and the editor Laurent Linnemer for their fruitful comments on an earlier draft of the paper. The usual caveat applies.

${ }^{\dagger}$ Toulouse School of Economics (INRA, IDEI), 21 allée de Brienne, 31000 Toulouse, France. E-mail: jean-pierre.amigues@inra.fr, corresponding author.

$\ddagger$ Toulouse School of Economics, Universit Toulouse Capitole (IDEI, IUF), Manufacture des Tabacs, 21 allée de Brienne, 31000 Toulouse, France. michel.moreaux@tse-fr.eu 


\begin{abstract}
Converting Primary Resources Into Useful Energy: The Pollution Ceiling Efficiency Paradox

We study an economy producing energy services from a polluting fossil fuel and a carbon free renewable resource under a constraint on the admissible atmospheric carbon concentration, equivalently under a constraint on the admissible temperature. The transformation rates of natural primary resources energy into useful energy are costly endogenous variables. Choosing higher efficiency rates requires to bring into operation more sophisticated energy transformation devices, that is more costly ones. We show that, independently of technical progress, along an optimal path, the transformation rate of any exploited resource should increase throughout time, excepted within the period during which the carbon constraint is binding, a phenomenon we call the 'ceiling paradox'. The effects of technical progress in the fossil fuel and the renewable energy sectors are strongly contrasted.
\end{abstract}

Keywords: energy efficiency; carbon pollution; non-renewable resources; renewable resources.

JEL classifications: Q00, Q32, Q43, Q54. 


\section{Introduction}

It is a well documented fact that historically, the conversion rate of primary energy into useful energy has steadily increased. For example, the first steam power units operated in the British mining industry to pump water, in the early eighteenth century, the steam engine of Thomas Newcomen (1712), converted about $0.5 \%$ of its potential energy input (coal and/or wood) into useful work output. About sixty years later $(1769)^{1}$, the Watt engine was converting $3 \%$ of its potential energy input, six times the performance of its ancestor. $^{2}$ Both engines were built according to some loose thermodynamic principles. ${ }^{3}$ However, a glance at the two engines design shows that the cooling system of the Watt engine was more sophisticated and more costly than the cooling system of the Newcomen machine. Improvement still went on during the nineteenth century and up to the middle of the twentieth century with more and more complex engines, especially by multiplying the number of cylinders and other devices for a better use of the steam produced in the boiler.

Although technical progress and growing scientific knowledge are certainly key explanations of the increasing efficiency of the energy uses in an historical perspective, ${ }^{4}$ the objective of this paper is to show that it may result more simply from the mere working of competitive forces promoting efficiency efforts in a world of nonrenewable energy resource scarcity even without technical progress. Choosing a conversion rate of available energy into useful energy is an economic choice and retaining a more efficient process is also, generally, more costly. For example some part of the exhausted energy resulting from the burning of gas in a today engine can be exploited, via a turbo-charger, to improve the efficiency of combustion. But one has to bear the cost of the turbo-charger and its installation in the car. In hybrid cars, some part of the energy which would be otherwise dissipated within

\footnotetext{
${ }^{1} 1769$ is the date of the first patent obtained by Watt. The first engines were sold by Boulton and Watt seven years later, in 1776 according to Marsden (2002, p 102).

${ }^{2}$ Both rates from (Kümmel, 2011, p49) for the Newcomen engine and p50 for the Watt engine. As usual, one must be cautious about such estimations. For example, (Brookes, 2000, p 359) gives respectively $0.75 \%$ for the Newcomen engine and $4 \%$ for the Watt engine. However the scale of the increase factor is about the same, the Watt engine being 5.33 times more efficient than the Newcomen machine.

${ }^{3}$ The first theoretical essay by Carnot (1824) was published only fifty years later.

${ }^{4}$ However note that technical progress is partly endogenous.
} 
the atmosphere, is used to save the gasoline consumption by transforming the energy contained within the exhaust gas into electricity which in turn is transformed into mechanical energy to propulse the car. But clearly two engines, a classical gas one and an electric one, are more costly than only one.

In this paper, we take explicitly into account the fact that to obtain useful energy from a fossil resource, it is first necessary to transform the underground energy into what we call available crude energy, an operation undertaken by the extractive industry, and next to transform the available crude energy into useful energy, a task generally performed jointly by utilities and the final users themselves. We assume that the unitary extraction costs depend negatively upon the resource grade under exploitation. Moreover, the cost of transforming one unit of the extracted resource into useful energy increases with the energy conversion rate. ${ }^{5}$

Transforming extracted fossil fuel into useful energy generates also as a by-product polluting GHG emissions in the atmosphere with potential adverse consequences. These emissions are more or less proportional to the burnt fossil resource rather than to the useful energy output. Hence, improving the conversion rate may be seen as an indirect abatement device. The diesel engines emit less $\mathrm{CO}_{2}$ per unit of gas than the gasoline engines because they are more efficient converters of potential energy, but they are also more costly to produce. However contrary to other abatement options, like carbon capture and sequestration installations, the conversion rate improvements simultaneously save the resource.

Several views of a climate change mitigation policy have been proposed in the climate economics literature. The most conventional one expresses the consequences of global warming as a combination of welfare losses (impacts on properties, health impacts) and productivity losses (e.g. agricultural yields losses). These losses are then aggregated as a 'damage' function, assumed to be some increasing function of the size of the atmospheric carbon stock (or of the average temperature rise). ${ }^{6}$ The design of an optimal environmental reg-

\footnotetext{
${ }^{5}$ Also important empirically is the recovery rate of available crude energy from the underground one. This problem requires a specific analysis outside the scope of the present paper.

${ }^{6}$ Multiple theoretical and empirical studies have endorsed the 'damage function' ap-
} 
ulation scheme is then accommodated in a Pigouvian way. An optimal global carbon tax should identify with the marginal climate damage in annualized value equivalent. Since the damages evolve through time with the climate dynamics, the tax rate should also be adjusted to the climate damages trend. An alternative policy to the implementation of a carbon tax, perhaps less demanding with respect to the commitment abilities of the governments, is the creation of carbon emissions permits markets. The time adjustment of the regulation is in this case achieved through a periodic revision of the quantity of allowances issued by the regulator.

Instead of a climate damage function framework, we follow in the present paper another route pioneered by Chakravorty, Magnd Moreaux (2006). In their model, carbon accumulation in the atmosphere creates only negligible damages provided that the pollution carbon stock stays under some critical threshold. However, this threshold be crossed over, earth climate conditions would become catastrophic. The objective of the environmental regulation should then be to limit the atmospheric carbon concentration below the threshold level. Such a modeling framework echoes the Paris Agreement proposal of avoiding an average earth temperature rise above $+2^{0} \mathrm{C}$ by the end of the current century. ${ }^{7}$

In our setting, the use of fossil fuels thus faces two kinds of constraints. The first one is the physical scarcity of the available fossil fuels reserves, the second one is the limited ability of the atmospheric compartment to store carbon emissions without triggering potentially damaging climate change. Raising the energy conversion rate of fossil fuels can alleviate these two constraints by saving the resource while mitigating carbon emissions.

An alternative to costly energy conversion efficiency efforts in fossil fuel

proach. Main original contributions are Tahvonen and Kuuluvainen (1991), Farzin and Tahvonen (1996), Withagen (1994) Tahvonen and Withagen (1996), Tahvonen (1997), Toman and Withagen (2000). For more recent contributions see Golosov et al. (2014), Van der Ploeg and Withagen (2014), Hassler et al. (2012), Nordhaus (2014), Stern (2007).

${ }^{7}$ As pointed out by Weitzman (2010) and Mason and Wilmot (2015), damages are depending on the temperature rather than directly on the carbon stock. Thus the ceiling should be defined as a temperature ceiling, like the well-known $+2^{0} \mathrm{C}$ ceiling. However as far as there exists a monotonic relationship between the temperature level and the atmospheric carbon stock, the qualitative properties of the optimal paths would be the same. The issue becomes more intricate when both the temperature level and the carbon stock size drive the temperature dynamics. 
exploitation is the development of carbon free renewable energy use. However, the transformation of clean energy primary sources into useful energy faces the same kind of physical and technical constraints than the exploitation of fossil fuels. We model this problem by assuming that the unitary production cost of useful energy from clean renewable energy increases with its production rate. We want to describe in this context the dynamics of the energy transition from fossil fuels toward clean energy.

Within this general framework, we show the following. When the demand function for useful energy is stationary, the optimal transformation rate of the fossil energy source broadly increases through time up to the end of its exploitation. The time and the grade at which exploitation ends are endogenously determined not only by the increasing costs of less accessible grades but also by the increasing transformation cost of crude energy into useful energy. When renewable energy is exploited in conjunction with fossil energy, it takes progressively a larger share inside the energy mix until it replaces completely the use of fossil energy.

Rather surprisingly, when a constraint on the atmospheric pollution stock is added, then the transformation rate in the coal industry must stay constant when coal is the only resource which is exploited within the time period during which the constraint is active. Maybe even more surprising, when the renewable resource is also exploited, its exploitation rate has also to be kept constant. Restricting the use of coal does not open more room to the nonpolluting renewable resource. The energy mix must stay unmodified. We call this feature of the optimal energy and climate policy under an atmospheric carbon stabilization constraint, the ceiling paradox.

Thus if something evolves under the ceiling regime when the atmospheric $\mathrm{CO}_{2}$ concentration is at its critical level, that must be the result of some technical progress. We show that technical progress has contrasted effects according to it is occurring in the fossil energy sector or in the renewable energy sector. In particular technical progress in the renewable energy sector only tends to deteriorate the efficiency of the fossil energy sector.

The paper is organized as follows. The model of useful energy production from primary resources is laid down in Section 2. Section 3 presents the optimality problem faced by the society and the main characteristics of the 
optimal policies. The optimal paths are described in Section 4. Section 5 is devoted to the effects of technical progress. Section 6 concludes. ${ }^{8}$

\section{A model of useful energy production from primary resources}

We consider a stationary economy in which final energy services, in brief the useful energy (U.E), can be obtained through the exploitation of two primary energy resources: a polluting fossil fuel ('coal' thereafter) and a clean and renewable resource ('solar' thereafter). Let $q_{x}(t)$ be the useful energy production rate resulting from the coal energy processing (C.U.E) and $q_{y}(t)$ be the production rate resulting from the solar energy processing (S.U.E). Assuming that C.U.E and S.U.E are perfect substitutes and that useful energy cannot be stored, we can define $q(t)$, the total U.E production rate, as the sum of the production resulting from the both processes: $q(t)=$ $q_{x}(t)+q_{y}(t)$.

\section{Users surplus}

Let $u(q)$ be the instantaneous user surplus generated by the consumption of $q$ units of U.E. We assume that the function $u(q)$ satisfies the following standard assumption A.1. ${ }^{9}$

Assumption A. $1 u: \mathbb{R}_{++} \rightarrow \mathbb{R}_{+}$, is twice continuously differentiable, strictly increasing, $u^{\prime}>0$, strictly concave, $u^{\prime \prime}<0$, with $u^{\prime}\left(0^{+}\right)=+\infty$ and $\lim _{q \uparrow \infty} u^{\prime}(q)=0$.

We sometimes use the notations $p(q)$ for the marginal surplus function $u^{\prime}(q)$, the inverse demand function, and $q^{d}(p)$ for the direct demand function, the inverse of $u^{\prime}(q)$, well defined under A.1.

\footnotetext{
${ }^{8}$ An alternative formulation as perfect foresight equilibrium is given in Amigues and Moreaux (2016).

${ }^{9}$ For any function $f$ defined on $X \subseteq \mathbb{R}$ and any $\bar{x} \in X$, we denote respectively by $f\left(\bar{x}^{+}\right)$ and $f\left(\bar{x}^{-}\right)$the $\operatorname{limits}_{\lim _{x \downarrow \bar{x}}} f(x)$ and $\lim _{x \uparrow \bar{x}} f(x)$, when such limits exist.
} 


\section{Coal mining}

Let $X(t)$ denote the coal stock not yet exploited at time $t$, measured in energy units, and let $X^{0}$ be the initial coal endowment: $X^{0}=X(0)$. The coal sites are ordered by cost merit order. Let $a(X)$ be the unit extraction cost of grade $X$, hence a total extraction cost $a(X(t)) x(t)$ for the coal extraction rate $x(t)$ at time $t$ when the grade $X(t)$ is exploited. The function $a(X)$ is assumed to satisfy the standard assumption A.2:

Assumption A. 2 a: $\left(0, X^{0}\right] \rightarrow \mathbb{R}_{+}$is twice continuously differentiable on $\left(0, X^{0}\right)$, strictly decreasing, $a^{\prime}(X)<0$, strictly convex, $a^{\prime \prime}(X)>0$, with $a\left(0^{+}\right)=+\infty$.

The last property in A.2, $a^{\prime}\left(0^{+}\right)=+\infty$, together with the later assumptions on the production cost in the S.U.E industry imply that some part of the initial coal endowment, $X^{0}$, would have to be kept underground. As we will show, this part of necessary un-burned coal does not depend upon its pollution content, even if the problem is to stay below some atmospheric pollution stock ceiling.

The coal useful energy industry

Transforming the coal primary energy into useful energy implies a loss. Let us denote by $\eta$ the transformation rate of coal primary energy into useful energy: $0<\eta \leq \bar{\eta}<1$, where $\bar{\eta}$ is the maximum conversion rate technologically feasible. Thus the C.U.E industry produces, at time $t, \eta(t) x(t)$ units of U.E from $x(t)$ units of coal energy: $q_{x}(t)=\eta(t) x(t)$.

The transformation, or conversion rate, $\eta(t), \eta(t) \in(0, \bar{\eta})$, is a decision variable. As explained in the introduction, choosing higher transformation rates requires to incur higher unitary transformation costs (per unit of processed coal input). Let us denote by $b(\eta)$ the conversion cost of one unit of coal energy into $\eta$ units of U.E. Then the total transformation cost of $x$ units of coal into $q_{x}=\eta x$ units of C.U.E amounts to $b(\eta) x$.

The unitary production cost of C.U.E, net of the extraction cost of coal, 
amounts to $b(\eta) / \eta$, equal to the marginal production cost, that is a total cost equal to $b(\eta) q_{x} / \eta$. We assume that this unit cost is an increasing function of the transformation rate. This implies that $b(\eta)$, the unit conversion cost should also be an increasing function of $\eta \cdot{ }^{10}$ The unit cost function satisfies the assumption A.3.

Assumption A. $3 b:[0, \bar{\eta}) \rightarrow \mathbb{R}_{+}$is twice continuously differentiable on $(0, \bar{\eta})$, strictly increasing, $b^{\prime}(\eta)>0$, strictly convex, $b^{\prime \prime}(\eta)>0$, with $b\left(0^{+}\right)=$ $0, b^{\prime}\left(0^{+}\right)>0, b\left(\bar{\eta}^{-}\right)=+\infty$ and $b^{\prime}\left(\bar{\eta}^{-}\right)=+\infty$. Furthermore the unit production cost of C.U.E in inputs other than coal, and so the marginal production cost, is a strictly increasing function of $\eta: b^{\prime}(\eta)>b(\eta) / \eta$ and $\lim _{\eta \downarrow 0} b(\eta) / \eta=\lim _{\eta \downarrow 0} b^{\prime}(\eta)>0$.

Burning coal to obtain, for example, electricity requires other inputs, at least equipments, hence a strictly positive marginal cost of C.U.E at $0^{+}$: $\lim _{\eta \downarrow 0} b(\eta) / \eta>0$. The same should apply to the derivative of the function $b($.$) at \eta=0^{+}$. The assumptions $b\left(\bar{\eta}^{-}\right)=+\infty$ and $b^{\prime}\left(\bar{\eta}^{-}\right)=+\infty$ mean that it is not physically possible to transform totally the potential energy of coal into useful energy. Assuming $b\left(\bar{\eta}^{-}\right)=+\infty$ and $b^{\prime}\left(\bar{\eta}^{-}\right)=+\infty$ allows some simplifications but does not modify the main qualitative properties of the optimal paths.

\section{Pollution}

Burning coal not only produces useful energy but also a pollution flow. Assume an homogenous pollution power among the different grades of coal. ${ }^{11}$ Denoting by $\zeta$ the common unitary pollution content of coal, the pollution flow generated by the transformation of $x(t)$ units of coal at time $t$ amounts to $\zeta x(t)$. This pollution flow feeds the pollution stock $Z(t)$. The pollution

${ }^{10}$ Differentiating the unit production cost of C.U.E yields:

$$
\frac{d}{d \eta} \frac{b(\eta)}{\eta}=\frac{1}{\eta}\left[b^{\prime}(\eta)-\frac{b(\eta)}{\eta}\right] .
$$

It is immediate that $b^{\prime}(\eta)>0$ is a necessary condition for $(d / d \eta)[b(\eta) / \eta]>0$.

${ }^{11}$ The issue of heterogenous polluting resources is thoroughly examined in Chakravorty et al. (2008). 
stock is self-dissolving at a proportional rate $\alpha, \alpha>0$, that we assume to be constant to simplify. ${ }^{12}$ Thus the dynamics of $Z(t)$ is given by:

$$
\dot{Z}(t)=\zeta x(t)-\alpha Z(t) \text {. }
$$

We denote by $Z^{0}$ the pollution stock inherited from the past.

The pollution stock is constrained to be at most equal to some critical level or ceiling, $\bar{Z}$, as in Chakravorty et al. (2006). This ceiling may, for example, results from an international climate agreement, provided that the agreement be enforced! In order that the model makes sense we must assume that $Z^{0}<\bar{Z}$. We denote by $\bar{x}$ the maximum consumption of the coal input by the C.U.E industry when the pollution is at the ceiling. From the dynamics of $Z$ with $\dot{Z}=0$ and $Z=\bar{Z}$, we get $\bar{x}=\alpha \bar{Z} / \zeta$.

\section{The solar useful energy industry}

We do not detail the production process in the S.U.E industry. It is not in this industry that lies what determines the qualitative properties of the optimal paths. We simply assume that $q_{y}$ is produced at an increasing marginal cost. Let $c\left(q_{y}\right)$ denote the cost of the S.U.E industry and $\bar{q}_{y}$ the upper bound of $q_{y}$. We assume that the solar energy production cost function satisfies the assumption A.4:

Assumption A. $4 c:\left[0, \bar{q}_{y}\right) \rightarrow \mathbb{R}_{+}$is twice continuously differentiable on $\mathbb{R}_{++}$, strictly increasing, $c^{\prime}\left(q_{y}\right)>0$, strictly convex, $c^{\prime \prime}\left(q_{y}\right)>0$, with $c(0)=0$ and both $c^{\prime}\left(0^{+}\right)>0, c^{\prime \prime}\left(0^{+}\right)>0$ and $c^{\prime}\left(\bar{q}_{y}\right)=+\infty$.

As for the C.U.E production, the S.U.E production requires other inputs than the solar radiation, hence $c^{\prime}\left(0^{+}\right)>0$.

Absent the C.U.E production the optimal S.U.E production is this production level solving $u^{\prime}\left(q_{y}\right)=c^{\prime}\left(q_{y}\right)$. We denote by $\tilde{q}_{y}(\equiv \tilde{q})$ this S.U.E production rate and by $\tilde{p}$ the corresponding U.E price: $\tilde{p}=u^{\prime}\left(\tilde{q}_{y}\right)$.

\footnotetext{
${ }^{12}$ A more realistic assumption would be to assume that $\alpha$ is some function of $Z$. See Forster (1975), Farzin (1996), Farzin and Tahvonen (1996), Tahvonen and Salo, (1996), Tahvonen and Withagen, (1996), Toman and Withagen, (2000), and Amigues and Moreaux, (2013), for more general formulations.
} 
In order that the coal be ever exploited we must assume that it is worth to be exploited, some kind of competitiveness assumption: The full average cost of the least costly way to produce C.U.E must be lower than $\tilde{p}$. The last costly coal input of the C.U.E industry is the coal of grade $X^{0}$ absent any mining rent. Under this condition and given that $q_{x} / \eta$ units of coal are required to produce $q_{x}$ with the conversion rate $\eta$, the total cost of $q_{x}$ amounts to $(1 / \eta)\left[a\left(X^{0}\right)+b(\eta)\right] q_{x}$. Minimizing the average cost $(1 / \eta)\left[a\left(X^{0}\right)+b(\eta)\right]$ (equal to the marginal cost) results in:

$$
-\frac{1}{\eta^{2}}\left[a\left(X^{0}\right)+b(\eta)\right]+\frac{1}{\eta} b^{\prime}(\eta)=0 \Longrightarrow b^{\prime}(\eta)-\frac{b(\eta)}{\eta}=\frac{a\left(X^{0}\right)}{\eta}
$$

Let $\eta_{e}$ ( $e$ for coal enters the competition) be the solution of the above equation (2.1). ${ }^{13}$ Then the coal competitiveness assumption reads:

Assumption A. 5 The C.U.E sector, the C.U.E industry together with the coal mining industry, is competitive, that is: $\tilde{p}>\left[a\left(X^{0}\right)+b\left(\eta_{e}\right)\right] / \eta_{e}$.

\section{Discounting and welfare}

The social rate of discount $\rho$ is strictly positive and constant through time. The social welfare is the sum of the discounted net surplus provided that the ceiling constraint be satisfied.

\footnotetext{
${ }^{13}$ The assumption A.2, $a\left(X^{0}\right)>0$, together with the assumption A.3 both imply that (2.1) has a unique positive solution.
} 


\section{The social planner problem and the main properties of the optimal paths}

\subsection{Social planner program and necessary optimality conditions}

The social planner determines a path $\left\{\left(\eta(t), x(t), q_{y}(t)\right)\right\}_{t=0}^{\infty}$ maximizing the social welfare, that is solves the following program $(S . P):{ }^{14}$

$$
\begin{aligned}
(S . P): \max _{\eta, x, q_{y}} & \int_{0}^{\infty}\left\{u\left(\eta(t) x(t)+q_{y}(t)\right)-a(X(t)) x(t)-b(\eta(t)) x(t)\right. \\
& \left.-c\left(q_{y}(t)\right)\right\} e^{-\rho t} d t \\
\text { s.t. } \quad & \dot{X}(t)=-x(t), \quad X(0)=X^{0} \quad \text { given } \\
& \dot{Z}(t)=\zeta x(t)-\alpha Z(t), Z(0)=Z^{0}<\bar{Z} \quad \text { given } \\
& \text { and } \bar{Z}-Z(t) \geq 0 \\
& \eta(t) \geq 0, x(t) \geq 0 \text { and } q_{y}(t) \geq 0
\end{aligned}
$$

Let $\lambda_{X}(t)$ and $-\lambda_{Z}(t)$ be the co-state variables of $X(t)$ and $Z(t)$ respectively; ${ }^{15} \nu(t)$ be the Lagrange multiplier associated to the ceiling constraint; $\gamma_{\eta}(t), \gamma_{x}(t)$ and $\gamma_{y}(t)$, be the Lagrange multipliers associated to the nonnegativity constraints on $\eta(t), x(t)$ and $y(t)$ respectively. The current value Hamiltonian, $\mathcal{H}$, and Lagrangian, $\mathcal{L}$, read: ${ }^{16}$

$$
\begin{aligned}
\mathcal{H} & =u\left(\eta x+q_{y}\right)-a(X) x-b(\eta) x-c\left(q_{y}\right)-\lambda_{X} x-\lambda_{Z}[\zeta x-\alpha Z] \\
\mathcal{L} & =\mathcal{H}+\nu[\bar{Z}-Z]+\gamma_{\eta} \eta+\gamma_{x} x+\gamma_{y} q_{y} .
\end{aligned}
$$

\footnotetext{
${ }^{14}$ We omit the constraint $\eta \leq \bar{\eta}$ which is never binding under A.3 and A.4. Also under A. 2 and A.4, the constraint $X(t) \geq 0$ is never active.

${ }^{15} \mathrm{By}$ choosing $-\lambda_{Z}(t)$ as the co-state variable of $Z(t), \lambda_{Z}(t)$ appears as the optimal opportunity cost of pollution, that is the optimal taxation rate of the polluting emissions flow.

${ }^{16}$ We omit the time argument absent any risk of confusion.
} 
The first order conditions are:

$$
\begin{aligned}
& \frac{\partial \mathcal{L}}{\partial \eta}=0 \quad \Longrightarrow u^{\prime}\left(\eta x+q_{y}\right) x=b^{\prime}(\eta) x-\gamma_{\eta} \\
& \frac{\partial \mathcal{L}}{\partial x}=0 \quad \Longrightarrow u^{\prime}\left(\eta x+q_{y}\right) \eta=a(X)+b(\eta)+\lambda_{X}+\zeta \lambda_{Z}-\gamma_{x} \\
& \frac{\partial \mathcal{L}}{\partial q_{y}}=0 \quad \Longrightarrow u^{\prime}\left(\eta x+q_{y}\right)=c^{\prime}\left(q_{y}\right)-\gamma_{y}
\end{aligned}
$$

together with the usual complementary slackness conditions.

The dynamics of the co-state variables, when time differentiable, satisfy:

$$
\begin{aligned}
\dot{\lambda}_{X}=\rho \lambda_{X}-\frac{\partial \mathcal{L}}{\partial X} \Longrightarrow & \dot{\lambda}_{X}=\rho \lambda_{X}+a^{\prime}(X) x \\
\dot{\lambda}_{Z}=\rho \lambda_{Z}+\frac{\partial \mathcal{L}}{\partial Z} \Longrightarrow & \dot{\lambda}_{Z}=(\rho+\alpha) \lambda_{Z}-\nu, \text { together with: } \\
& \nu \geq 0, \text { and } \nu[\bar{Z}-Z]=0
\end{aligned}
$$

Last the transversality condition at infinity is:

$$
\lim _{t \uparrow \infty} e^{-\rho t}\left[\lambda_{X}(t) X(t)+\lambda_{Z}(t) Z(t)\right]=0
$$

\subsection{General properties of the optimal paths}

\subsubsection{Hotelling rule}

The equation (3.8) expresses the Hotelling rule when the extraction costs depend upon the grade which is exploited. Here $\lambda_{X}(t)$ is the mining rent of the grade $X(t)$ exploited at time $t$. Under constant marginal costs, when the extraction cost is the same for all grades, the rent must increase at a proportional rate equal to the social rate of discount, that is by $\rho \lambda_{X}(t)$, between $t$ and $t+d t$. In the present context the extraction cost is larger at $t+d t$ than at $t$ by an amount approximatively equal to $-a^{\prime}(X(t)) x(t) d t{ }^{17}$ Thus the mining rent of the grade $X(t+d t)$ must be equal to $\lambda_{X}(t+d t)=$ $\lambda_{X}(t)+\rho \lambda_{X}(t)+a^{\prime}(X(t)) x(t) d t$, hence (3.8), if the mining rent of the grade

\footnotetext{
${ }^{17}$ Remember that $a^{\prime}(X)$ is negative.
} 
$X(t)$ is equal to $\lambda_{X}(t)$, in order that the extraction of $x(t)$ be not postponed to $t+d t$ and the extraction of $x(t+d t)$ be not switched earlier at $t$. Thus (3.8) is the local arbitrage condition which must hold at any time along the optimal path during the period of coal exploitation.

It is not clear from (3.8) that the mining rent path is monotonous. ${ }^{18}$ However the full marginal cost of coal, the sum of the marginal extraction cost, $a(X(t))$, and the mining rent of the grade, $\lambda_{X}(t)$, must grow during the time period of coal exploitation. ${ }^{19}$ Time differentiating $a(X(t))+\lambda_{X}(t)$ and substituting (3.8) for $\dot{\lambda}_{X}(t)$, we obtain:

$\dot{a}(X(t))+\dot{\lambda}_{X}(t)=-a^{\prime}(X(t)) x(t)+\rho \lambda_{X}(t)+a^{\prime}(X(t)) x(t)=\rho \lambda_{X}(t)>0$.

From now we denote by $w(t)$ the full marginal cost of coal for the mining industry: $w(t)=a(X(t))+\lambda_{X}(t)$ and rewrite (3.6) as:

$$
u^{\prime}\left(\eta(t) x(t)+q_{y}(t)\right) \eta(t)=w(t)+b(\eta(t))+\zeta \lambda_{Z}(t) .
$$

\subsubsection{Shadow marginal cost of pollution}

Initially $\nu=0$ since $Z^{0}<\bar{Z}$. Thus denoting by $\underline{t}_{Z}$, the time at which the ceiling constraint begins to bind, we get from (3.9):

$$
\lambda_{Z}(t)=\lambda_{Z 0} e^{(\rho+\alpha) t}, t \leq \underline{t}_{Z}, \text { where } \lambda_{Z 0} \equiv \lambda_{Z}(0) .
$$

Once the ceiling constraint is no more active and forever, pollution is no more a problem and its shadow marginal cost must be nil. Let $\bar{t}_{Z}$ be the time at which ends the phase at the ceiling, then:

$$
\lambda_{Z}(t)=0, t \geq \bar{t}_{Z} .
$$

\footnotetext{
${ }^{18}$ Note that, absent a renewable substitute, the mining rent could grow indefinitely. See Krulce (1993) for a sufficient condition of monotically increasing rent in this case. For more recent developments, see Hart (2016).

${ }^{19}$ However note that the discounted rent, $\lambda_{X}(t) e^{-\rho t}$, is unambiguously decreasing. Differentiating and substituting (3.8) for $\dot{\lambda}_{X}(t)$, results in:

$$
\frac{d}{d t}\left(\lambda_{X}(t) e^{-\rho t}\right)=a^{\prime}(X(t)) e^{-\rho t}<0 .
$$
}


What remains to determine, and will be determined later (see (3.20)), is the path of $\lambda_{Z}(t)$ during the phase at the ceiling, when $\nu(t)>0$.

\subsubsection{Optimal conversion rates}

The optimality conditions (3.5)-(3.6) can be interpreted as conditions of current profit maximization of the U.E industry at time $t$ given an U.E price $p$ equal to $u^{\prime}$, a price of the coal input equal to its full marginal cost, $w$, and a levy on the polluting emissions equal to the shadow marginal cost of the pollution stock $\lambda_{Z}$, that is $\zeta \lambda_{Z}$ per unit of processed coal. Thus the current profits of the C.U.E industry denoted by $\pi_{c}(t)$ amount to:

$$
\pi_{c}(t)=p(t) \eta(t) x(t)-\left[w(t)+\zeta \lambda_{Z}(t)\right] x(t)-b(\eta(t)) x(t) .
$$

The f.o.c's of the profit maximization w.r.t. $\eta(t)$ and $x(t)$, assuming that the profit maximizing pair $(\eta(t), x(t))$ is strictly positive, are:

$$
\begin{aligned}
& \frac{\partial \pi_{c}}{\partial \eta}=0 \Longrightarrow p x=b^{\prime}(\eta) x \Longrightarrow p=b^{\prime}(\eta), \text { that is }(3.5) \\
& \frac{\partial \pi_{c}}{\partial x}=0 \Longrightarrow p \eta=w(t)+\zeta \lambda_{Z}+b(\eta), \text { that is }(3.6) .
\end{aligned}
$$

The equation (3.5) determines the optimal energy transformation rate, $\eta$, as a function of the U.E price. In order that the C.U.E industry be active the U.E price must be at least equal to $b^{\prime}\left(0^{+}\right)$.

Let us denote by $\omega(t)$ the full marginal (and average) user cost of the coal input for the C.U.E industry, the sum of the coal unitary cost and the tax having to be born for its processing: $\omega(t)=w(t)+\zeta \lambda_{Z}(t)=a(X(t))+$ $\lambda_{X}(t)+\zeta \lambda_{Z}(t)$. The unitary cost of the C.U.E is the sum of the coal input by units of C.U.E, $\omega(t) / \eta(t)$ and the cost of the other inputs $b(\eta(t)) / \eta(t)$. This unitary cost is minimized for $\eta(t)$ such that the derivative w.r.t. $\eta$ is nil, that is:

$$
\frac{d}{d \eta}\left\{\frac{\omega+b(\eta)}{\eta}\right\}=0 \quad \Longrightarrow \quad b^{\prime}(\eta) \eta=b(\eta)+\omega .
$$

Since $b^{\prime}(\eta)=p$ by (3.5) then the above condition is nothing but than (3.6). 
The equation (3.14) defines the optimal conversion rate and the U.E price as functions of $\omega$. Let us denote respectively by $\eta^{*}(\omega)$ and $p^{*}(\omega)$ these two functions. Differentiating (3.14), we get:

$$
\frac{d \eta^{*}}{d \omega}=\frac{1}{b^{\prime \prime}\left(\eta^{*}\right) \eta^{*}}>0 \text { and } \frac{d p^{*}}{d \omega}=\frac{1}{\eta^{*}}>0
$$

We may use (3.15) to define the optimal coal input use of the C.U.E industry and the optimal C.U.E and S.U.E production rates as functions of $\omega$ to determine their move during the different phases of the optimal path.

\subsubsection{Optimal coal extraction rate, C.U.E and S.U.E productions}

Let us denote by $x^{*}(\omega), q_{x}^{*}(\omega), q_{y}^{*}(\omega)$ and $p^{*}(\omega)$ respectively the optimal coal extraction rate, C.U.E production rate, S.U.E production rate and U.E price as functions of $\omega, p^{*}(\omega)=u^{\prime}\left(q^{*}(\omega)\right)$, where $q^{*}(\omega)=q_{x}^{*}(\omega)+q_{y}^{*}(\omega)$ is the total U.E production as a function of $\omega$.

Assume first that only C.U.E is produced: $p^{*}(\omega)<c^{\prime}\left(0^{+}\right)$. In this case the f.o.c (3.6) may be rewritten as:

$$
u^{\prime}\left(\eta^{*}(\omega)\right) \eta^{*}(\omega)=b\left(\eta^{*}(\omega)\right)+\omega .
$$

Differentiating and taking into account that $b^{\prime}=u^{\prime}$, we get:

$$
p^{*}(\omega)<c^{\prime}\left(0^{+}\right) \Longrightarrow \frac{d x^{*}}{d \omega}=\frac{1-u^{\prime \prime} \eta^{*} x\left(d \eta^{*} / d \omega\right)}{u^{\prime \prime}\left(\eta^{*}\right)^{2}}<0 .
$$

Since $d p^{*} / d \omega>0$, from $u^{\prime}\left(q_{x}\right)=p^{*}(\omega)$, we obtain:

$$
p^{*}(\omega)<c^{\prime}\left(0^{+}\right) \Longrightarrow \frac{d q_{x}^{*}}{d \omega}=\frac{1}{u^{\prime \prime}} \frac{d p^{*}}{d \omega}<0 .
$$

Consider now the case in which both energies are exploited: $p^{*}(\omega)>$ $c^{\prime}\left(0^{+}\right)$. In this case, (3.5) and (3.6) may be rewritten as:

$$
\begin{aligned}
& u^{\prime}\left(\eta^{*}(\omega) x+q_{y}\right)=b\left(\eta^{*}(\omega)\right)+\omega \\
& u^{\prime}\left(\eta^{*}(\omega) x+q_{y}\right)=c^{\prime}\left(q_{y}\right) .
\end{aligned}
$$


Differentiating, we obtain:

$$
\left[\begin{array}{cc}
u^{\prime \prime}\left(\eta^{*}\right)^{2} & u^{\prime \prime} \eta^{*} \\
u^{\prime \prime} \eta^{*} & u^{\prime \prime}-c^{\prime \prime}
\end{array}\right]\left[\begin{array}{l}
d q_{x} \\
d q_{y}
\end{array}\right]=\left[\begin{array}{c}
-u^{\prime \prime} \eta^{*} x\left(d \eta^{*} / d \omega\right)+1 \\
-u^{\prime \prime} x\left(d \eta^{*} / d \omega\right)
\end{array}\right] d \omega,
$$

hence if $p^{*}(\omega)>c^{\prime}\left(0^{+}\right)$:

$$
\begin{aligned}
& \frac{d x^{*}}{d \omega}=-\frac{u^{\prime \prime} c^{\prime \prime} \eta^{*} x-\left(d \eta^{*} / d \omega\right)+u^{\prime \prime}-c^{\prime \prime}}{u^{\prime \prime} c^{\prime \prime}\left(\eta^{*}\right)^{2}}<0 \\
& \frac{d q_{y}^{*}}{d \omega}=\frac{1}{\eta^{*}}>0, \frac{d \eta^{*}}{d \omega}=\frac{1}{u^{\prime \prime}} \frac{d p^{*}}{d \omega}<0 \text { and } \frac{d q_{x}^{*}}{d \omega}=\frac{d q^{*}}{d \omega}-\frac{d q_{y}^{*}}{d \omega}<0 .
\end{aligned}
$$

We know that within the phase not constrained by the cap on the pollution stock, $\dot{\omega}(t)=\rho \lambda_{X}(t)+\zeta \dot{\lambda}_{Z}(t)$ with $\dot{\lambda}_{Z}(t) \geq 0$, hence $\dot{\omega}(t)>0$ as far as the coal resource is exploited, so that by (3.15)-(3.19), the moves of $p, \eta, x$, $q_{x}$ and $\eta_{y}$ are easily determined.

The proposition P.1 summaries the implications of (3.11)-(3.13) and (3.15)(3.19).

\section{Proposition P. 1 Unconstrained dynamics.}

Along the optimal path, during any time period of unconstrained coal exploitation:

a. The price of useful energy, $p(t)$, increases hence the production and consumption of useful energy, $q(t)$, decreases.

b. The shadow marginal cost of pollution, $\lambda_{Z}(t)$, either increases if the pollution stock ceiling is not yet attained, or is nil if the pollution stock constraint will no more bind in the future.

$c$. The conversion rate of coal into useful energy, $\eta(t)$, increases, the coal extraction rate, equivalently the coal input used by the coal useful energy industry, $x(t)$, decreases. 
d. When both energies are exploited, the production of solar useful energy, $q_{y}(t)$, increases. The aggregate production, $q(t)$, being time decreasing, the production of coal useful energy drops by an even higher rate, and the same applies to the polluting emissions.

Consider now the phase at the ceiling, if any. Then $x(t)=\bar{x}$, and since $d x^{*} / d \omega>0$, it must be the case that $\omega(t)=\bar{\omega}$, a constant. This in turn implies that the conversion rate of the coal energy into useful energy is constant during the phase at the ceiling. Although reducing the emissions per UE means increasing the conversion rate, the only way to increase the consumption rate of C.U.E when the pollution constraint is binding, the best is to stay with a constant conversion rate.

Furthermore when the solar source is exploited, although increasing the S.U.E production rate is the only other way to increase the useful energy consumption, the S.U.E production level too must be constant. We call this phenomenon the 'ceiling paradox': When the pollution stock is at its maximum size, do nothing to increase the consumption of useful energy even if what could be done would not increase the polluting emissions.

Last, because $\omega(t)$ is constant at the level $\bar{\omega}$ while $\dot{a}(X(t))+\lambda_{X}(t)=$ $\rho \lambda_{X}(t)$, then:

$$
\dot{\lambda}_{Z}(t)=\frac{d}{d t} \frac{1}{\zeta}\left[\bar{\omega}-\left(a(X(t))+\lambda_{X}(t)\right)\right]=-\frac{\rho}{\zeta} \lambda_{X}(t)<0 .
$$

The proposition P.2 summaries the characteristics of the optimal path during the climate constrained phase.

\section{Proposition P. 2 Constrained dynamics: the ceiling paradox.}

Along the optimal path, during a period of constrained coal exploitation:

a. The price of useful energy, $p(t)$, is constant hence its production and consumption, $q(t)$. 
$b$. The shadow marginal cost of pollution, $\lambda_{Z}(t)$, decreases so that the full marginal cost of the coal input in the coal useful energy industry, $\omega(t)$, is constant.

c. The conversion rate of the coal resource into useful energy, $\eta(t)$, is constant and since the consumption of coal by the coal useful energy industry is constant, $x(t)=\bar{x}$, then the production of coal useful energy, $q_{x}(t)$, is constant.

d. When the solar energy is simultaneously exploited, the production of solar useful energy, $q_{y}(t)$, is also constant.

The Corollary 1 is a direct implication of the Propositions 1 and 2 .

\section{Corollary 1 Starting of the solar energy production.}

The production of useful solar energy, if not started immediately at time $t=0$, must begin either before the phase at the ceiling if $p^{*}(\bar{\omega})>c^{\prime}\left(0^{+}\right)$, or either after this phase if the reverse holds, but never during the phase.

\section{Optimal paths}

Assuming that the ceiling constraint is binding along the optimal path, we first determine the number of constrained and unconstrained phases and their necessary sequence.

Since $Z^{0}<\bar{Z}$, the first phase of any optimal program is an unconstrained phase during which the coal consumption of the C.U.E industry is larger than $\bar{x}$ and decreasing. That $x(t)$ must be larger than $\bar{x}$ is necessary in order that $Z(t)$ increases from $Z^{0}$ up to $\bar{Z}$ and the ceiling constraint be binding along the path. Thus the next phase begins at the time $\underline{t}_{Z}$ at which $Z(t)=\bar{Z}$.

The following phase is thus necessarily a constrained phase. If not, the coal consumption of the C.U.E industry will go on decreasing and the ceiling 
will never be hit again since during an unconstrained phase the use of coal decreases. ${ }^{20}$

The problem is to determine the kind of phase following the constrained phase, either an unconstrained phase of coal exploitation or a phase of exclusive S.U.E consumption. Let us show that the right option is the first one.

The proof is by contradiction. Assume that the phase following the constrained one is a phase of exclusive S.U.E consumption. Since the optimal energy price path must be time continuous then $p(t)=\tilde{p}$ within both the constrained phase and the following one, where $\tilde{p}$ is the constant price along an exclusive S.U.E consumption path. Thus the total U.E consumption is constant too and equal to $\tilde{q}$. Let us denote by $\hat{\eta}$, the constant transformation rate during the constrained phase, hence a C.U.E consumption $q_{x}(t)=\hat{q}_{x}=\hat{\eta} \bar{x}$ during the phase. Thus at $\bar{t}_{Z}$ the S.U.E consumption should jump from $\tilde{q}-\hat{q}$ up to $\tilde{q}$. But from the f.o.c (3.7) relative to $q_{y}$ we must have:

$$
c^{\prime}\left(\tilde{q}-q_{x}\right)=\tilde{p}=c^{\prime}(\tilde{q})
$$

the 1.h.s equality holding at $\bar{t}_{Z}^{-}$and the r.h.s holding at $\bar{t}_{Z}^{+}$, a contradiction since $c^{\prime}\left(q_{y}\right)$ is strictly increasing.

Since the phase following the first phase at the ceiling is an unconstrained phase with C.U.E consumption, then the coal input use decreases, $x(t)<\bar{x}$, $t>\bar{t}_{Z}$, so that starting from $\bar{Z}$ at the beginning of the phase, the pollution stock never comes back later to the level $\bar{Z}$. That means that there is only one phase at the ceiling, after which the shadow marginal cost of pollution is forever nil: $\lambda_{Z}(t)=0, t \geq \bar{t}_{Z}$.

Although the duration of the period of coal exploitation is not necessarily finite because the extraction cost depends upon the cumulated extraction (c.f. Salant et al., 1983), the cumulated coal extraction is well defined. The mining rent, $\lambda_{X}(t)$, is nil either asymptotically, if $t_{X}=+\infty$, or from some finite time $t_{X}$, and since the last phase of coal exploitation is an unconstrained phase, then $\lambda_{Z}(t)$ too is nil so that $\omega(t)$ tends to some $a(\tilde{X})$ where $\tilde{X}$ is the stock of un-burned coal. Because the useful energy price tends toward $\tilde{p}$ then $\eta(t)$

\footnotetext{
${ }^{20}$ We show in Appendix A.1 that if $\bar{Z}$ is attained only at an isolated time then $\lambda_{Z}(t)=0$, $t \geq 0$ and the ceiling constraint may be forgotten.
} 
tends toward some definite value $\tilde{\eta}, \tilde{\eta}<\bar{\eta}$, and $\tilde{X}$ is this stock $X$ solving $[a(X)+b(\tilde{\eta})] / \tilde{\eta}=\tilde{p}$ (see Figure 1). Because under A.2, $\lim _{X \downarrow 0} a(X)=+\infty$, then $\tilde{X}>0$.

Figure 1 about here

The proposition P.3 sums up the properties of the optimal path not yet listed in the propositions P.1 and P.2.

Proposition P. 3 Optimal paths. Any optimal path along which the ceiling constraint binds includes at least three main time phases:

a. A first phase $\left[0, \underline{t}_{Z}\right), 0<\underline{t}_{Z}$, of unconstrained coal exploitation during which the coal input consumption by the C.U.E industry is larger than $\bar{x}$ and decreasing down to $\bar{x}$ at the end of the phase while the shadow marginal cost of pollution increases up to its maximum at the same date $\underline{t}_{Z}$ when $Z(t)$ hits the ceiling $\bar{Z}$;

b. A second phase, $\left[\underline{t}_{Z}, \bar{t}_{Z}\right), \underline{t}_{Z}<\bar{t}_{Z}$, of constrained coal exploitation, $x(t)=\bar{x}$, during which the shadow marginal cost of pollution decreases from its maximum, $\lambda_{Z}\left(\underline{t}_{Z}\right)$, at the beginning of the phase, down to 0 at the time $\bar{t}_{Z}$, the end of the phase;

c. A third phase, $\left(\bar{t}_{Z}, t_{X}\right), \bar{t}_{Z}<t_{X} \leq+\infty$, of unconstrained coal exploitation during which the coal extraction decreases from $\bar{x}$ down to 0 either asymptotically if $t_{X}=+\infty$, or at the end of the phase if $t_{X}<+\infty$. In any case, the conversion rate of coal into useful energy tends towards a definite upper limit, $\tilde{\eta}, \tilde{\eta}<\bar{\eta}$, and the cumulated coal extraction tends toward $X^{0}-\tilde{X}<X^{0}$, that is the stock $\tilde{X}, \tilde{X}>0$, is left un-burned. Simultaneously the production of solar useful energy increases and tends toward $\tilde{q}_{y}$;

d. The production of useful solar energy begins either within the first phase, $\left[0, \underline{t}_{Z}\right)$, if $c^{\prime}\left(0^{+}\right)$is lower than the U.E price at the ceiling, $c^{\prime}\left(0^{+}\right)<p^{*}(\bar{\omega})$, or during the third one, $\left(\bar{t}_{Z}, t_{X}\right)$, in the alternative case $c_{y}^{\prime}\left(0^{+}\right)>p^{*}(\bar{\omega})$. 
e. If $t_{X}<\infty$, then the fourth and last phase is a phase, $\left[t_{X}, \infty\right)$, of infinite duration during which the solar useful energy is the only available useful energy.

A typical optimal price path is illustrated in Figure 2 for the case $t_{X}<$ $+\infty .^{21}$

Figure 2 about here

The paths of useful energy production are illustrated in Figure 3, and the paths of coal extraction and C.U.E production are illustrated in Figure 4, both for the case of a S.U.E production beginning within the first phase $\left(0, \bar{t}_{Z}\right)$ and $t_{X}<+\infty .^{22}$

Figure 3 about here

Figure 4 about here

\section{Technical progress}

As stressed in the introduction, technical progress is currently put forward as the main explanation for energy efficiency improvements in economic history. Although a full fledged analysis of the effects of technical progress is outside the scope of the paper, the way technical advances could affect the properties

\footnotetext{
${ }^{21}$ We show in Appendix A.2 that the price path is time differentiable both at the time at which begins the S.U.E production and the time at which ends the coal exploitation when $t_{X}<+\infty$. Hence, the qualitative properties of the price path illustrated in Figure 2 do not depend upon the time at which the S.U.E production must be started. Therefore we do not record on the figure the time $t_{y}$ at which the S.U.E production begins.

${ }^{22}$ We show in Appendix A.2 that although $q(t)$ is time differentiable at $t_{y}$, both $q_{x}(t)$ and $q_{y}(t)$ are not time differentiable.
} 
of the optimal path is worth some developments. We abstract from the possibility of technological revolutions in U.E production or from improvements in the extraction techniques of the mining industry and focus the analysis on the consequences of smooth and exogenous improvements of the fossil or the renewable energy conversion techniques, in the form of a continuous down drift of the transformation cost curves over time.

We first consider the consequences of technical progress in C.U.E. production on the dynamics of both unconstrained and constrained time phases before proceeding to a similar analysis for the case of S.U.E production.

\subsection{Technical progress in useful coal energy production}

Let $b(\eta, t)$ denote the unit fossil energy conversion cost as a time dependent function, $\partial b(\eta, t) / \partial \eta$, be the corresponding time dependent marginal cost curve and assume that $\partial b / \partial t<0$ together with $\partial^{2} b / \partial \eta \partial t<0$. We have shown earlier (c.f. section 3, paragraph 3.2.3) that without technical progress, for a given $\omega$, the optimal transformation rate $\eta$ is determined as the solution of the equation (3.14):

$$
\frac{\omega}{\eta}=b^{\prime}(\eta)-\frac{b(\eta)}{\eta} \equiv \delta(\eta) .
$$

With technical progress the optimal transformation rate is determined as the solution of (c.f eq (A.3.4)), Appendix 3):

$$
\frac{\omega}{\eta}=\frac{\partial b(\eta, t)}{\partial \eta}-\frac{b(\eta, t)}{\eta} \equiv \delta(\eta, t) .
$$

Thus for drifts preserving the difference between the marginal and average costs of the transformation rate $\delta(\eta, t)$ for all $\eta \in(0, \bar{\eta})$, the function $\eta^{*}(\omega, t)$ giving the optimal rate as a function of the full marginal user cost of coal and time is time independent:

$$
\frac{\partial \delta(\eta, t)}{\partial t}=0 \Longrightarrow \frac{\partial^{2} b(\eta, t)}{\partial \eta \partial t}-\frac{1}{\eta} \frac{\partial b(\eta, t)}{\partial t}=0 .
$$

In this case (5.1) below reduces to:

$$
\dot{\eta}=\frac{1}{\eta \partial^{2} b / \partial \eta^{2}} \dot{\omega}>0
$$




\section{Figure 5 about here}

\subsubsection{Dynamics over the unconstrained phases}

We show in appendix A.3 that the optimal dynamics of the model variables during an unconstrained time phase obey:

$$
\begin{aligned}
\dot{\eta}= & \frac{1}{\eta \partial^{2} b / \partial \eta^{2}}\left[\frac{\partial b}{\partial t}-\eta \frac{\partial^{2} b}{\partial \eta \partial t}+\dot{\omega}\right] \\
\dot{x}= & \frac{x}{\eta^{2} \partial^{2} b / \partial \eta^{2}}\left[\frac{\partial^{2} b}{\partial \eta \partial t} \eta-(1+\theta)\left(\frac{\partial b}{\partial t}+\dot{\omega}\right)\right] \\
& \text { where } \theta \equiv \frac{\partial^{2} b}{\partial \eta^{2}}\left(\frac{u^{\prime \prime}-\partial^{2} c / \partial q_{y}^{2}}{u^{\prime \prime} x \partial^{2} c / \partial q_{y}^{2}}\right)>0 \\
\dot{q}_{x}= & -\frac{\theta x}{\eta \partial^{2} b / \partial \eta^{2}}\left[\frac{\partial b}{\partial t}+\dot{\omega}\right] \\
\dot{q}_{y}= & \frac{1}{\eta c^{\prime \prime}}\left[\frac{\partial b}{\partial t}+\dot{\omega}\right] \\
\dot{q}= & \frac{1}{\eta u^{\prime \prime}}\left[\frac{\partial b}{\partial t}+\dot{\omega}\right] \quad \text { and } \quad \dot{p}=\frac{1}{\eta}\left[\frac{\partial b}{\partial t}+\dot{\omega}\right] .
\end{aligned}
$$

For cost curves distance preserving drifts, we have already shown that the coal energy conversion performance increases as in the no technical progress case. This result carries over to a drift progressively reducing the vertical distance between the marginal and average cost curves since $\partial b / \partial t-\eta \partial^{2} b / \partial \eta \partial t>0$ implies also that $\dot{\eta}>0$.

The production of useful coal energy increases over time with a sufficiently fast technical progress. From (5.3) we get:

$$
\dot{q}_{x}(t)>0 \Longleftrightarrow \dot{\omega}(t)<-\frac{\partial b}{\partial t} .
$$

Note that this phenomenon can arise for any variation of the distance between the average and the marginal cost curve. That the useful coal energy production rate may increase because of technical progress is an illustration 
of the so-called rebound effect in the energy literature. ${ }^{23}$

A time increasing trend of the production of coal useful energy means a decline of the energy price and an increase of the aggregate useful energy production rate (see (5.5)). The useful renewable energy production rate hence decreases (see (5.4)) thus useful coal energy takes a larger share of the energy mix. It may even be the case that the coal extraction rate increases over time because of a very fast technical progress, the so-called 'backfire' effect of the energy literature. Making use of (5.2):

$$
\dot{x}(t)>0 \Longleftrightarrow-\left(\frac{\partial b}{\partial t}+\dot{\omega}\right)>\frac{1}{1+\theta} \frac{\partial^{2} b}{\partial \eta \partial t} \eta
$$

Observe that a 'backfire' of coal energy consumption can only happen in a scenario of decreasing energy prices and declining renewable energy production rates.

When technical progress generates increases of $\delta(\eta, t)$, that is if $\partial b / \partial t-$ $\eta \partial^{2} b / \partial \eta \partial t<0$, it is even possible that $\dot{\eta}<0$ (see (5.1)). Note that in such a situation, we get through (5.3)-(5.5):

$$
\begin{aligned}
\dot{\eta}<0 & \Longrightarrow \frac{\partial b}{\partial t}-\eta \frac{\partial^{2} b}{\partial \eta \partial t}+\dot{\omega}<0 \Longrightarrow \frac{\partial b}{\partial t}+\dot{\omega}<\eta \frac{\partial^{2} b}{\partial \eta \partial t}<0 \\
& \Longrightarrow \dot{p}<0 ; \dot{q}_{y}<0 ; \dot{q}>0 ; \dot{q}_{x}=\dot{\eta} x+\eta \dot{x}>0 \Longrightarrow \dot{x}>0 .
\end{aligned}
$$

Hence a deterioration of the coal energy conversion performance because of technical progress in the C.U.E. industry may only happen in a rather perverse episode during which the production of coal energy would expand, the energy price would decrease together with the renewable energy production, and the coal consumption would increase and thus also the carbon emissions.

\footnotetext{
${ }^{23}$ The possibility of rebound was first noticed by Jevons (1865). For a recent exposition see Brookes (2000) and Khazoom (1980).
} 


\subsubsection{The constrained phase}

Turn now to the climate constrained regime when the 'ceiling paradox' occurs in the original model. We show in appendix A.3.2 that:

$$
\begin{aligned}
& \dot{\eta}>0 \text { and } \dot{q}_{x}=\dot{\eta} \bar{x}>0 \\
& \dot{q}_{y}<0 \\
& \dot{q}>0 \text { and } \dot{p}<0 .
\end{aligned}
$$

Hence, contrarily to the original model, the useful energy price decreases and the aggregate production rate of U.E. increases during the constrained phase. The energy price being declining, the production of renewable U. E. should also decrease (see (5.4)). Since $q_{x}(t)=\eta(t) \bar{x}$ and $\dot{q}_{x}(t)=\dot{q}(t)-\dot{q}_{y}(t)>$ 0 , the economy increases its energy conversion performance, $\dot{\eta}(t)>0$. The cost reduction induced by technical progress translates in improvements of the coal energy performance, sustaining an increase of coal U.E. delivery and a parallel fall of renewable U.E. delivery.

Because of technical advances in fossil useful energy generation, the economy relies more and more on fossil fuels, experiencing a sort of 'reverse energy transition' from renewables back to coal energy. Introducing technical progress in C.U.E production results in an even more paradoxical conclusion as in the original model. Facing the climate constraint and benefiting from less costly conversion techniques for coal energy thanks to technical improvements, the economy relies more on fossil fuels and shrinks down the renewable energy production. Instead of a constant energy price, technical progress induces declining prices and useful energy consumption increases.

Turning to the dynamics of the shadow cost of coal use:

$$
\dot{\omega}=\frac{1}{\Delta}\left\{\frac{\partial b}{\partial t}\left[u^{\prime \prime}-\frac{\partial^{2} c}{\partial q_{y}^{2}}\right] \frac{\partial^{2} b}{\partial \eta^{2}}-u^{\prime \prime} \bar{x} \frac{\partial^{2} c}{\partial q_{y}^{2}}\left[\eta \frac{\partial^{2} b}{\partial \eta \partial t}-\frac{\partial b}{\partial t}\right]\right\} .
$$

where:

$$
\Delta=\frac{\partial^{2} b}{\partial \eta^{2}} \frac{\partial^{2} c}{\partial q_{y}^{2}}-u^{\prime \prime}\left[\frac{\partial^{2} b}{\partial \eta^{2}}+\bar{x} \frac{\partial^{2} c}{\partial q_{y}^{2}}\right]>0
$$


If $\delta(\eta, t)$ stays constant, $\partial^{2} b / \partial \eta \partial t-(1 / \eta) \partial b / \partial t=0$ implies that $\dot{\omega}>0$.

Last, time differentiating the f.o.c relative to $x, u^{\prime} \eta=w+b+\zeta \lambda_{Z}$, while taking into account that $\partial b / \partial \eta=u^{\prime}$ by the f.o.c relative to $\eta$, we get:

$$
u^{\prime \prime} \eta \dot{q}-\dot{w}-\frac{\partial b}{\partial t}=\zeta \dot{\lambda}_{Z} .
$$

Since the first two terms of the l.h.s are negative and the third one is positive we cannot conclude, although on average $\dot{\lambda}_{Z}$ must be negative since $\lambda_{Z}$ tends to 0 at the end of the period.

\subsection{Technical progress in useful solar energy production}

Let $c(y, t)$ denote the production cost function of S.U.E and assume that both $\partial c / \partial t<0$ and $\partial^{2} c / \partial y \partial t<0$ : the solar useful energy industry benefits from a continuous drift down of its production cost both on average and at the margin.

\subsubsection{Unconstrained time phases}

The dynamics of the variables now obey (see Appendix A.3 for a proof):

$$
\begin{aligned}
\dot{\eta} & =\frac{1}{\eta \partial^{2} b / \partial \eta^{2}} \dot{\omega} \\
\dot{x} & =\frac{x}{\eta^{2} \partial^{2} b / \partial \eta^{2}}\left[\frac{\eta}{x} \frac{\partial^{2} b / \partial \eta^{2}}{\partial^{2} c / \partial q_{y}^{2}} \frac{\partial^{2} c}{\partial q_{y} \partial t}-\dot{\omega}(1+\theta)\right] \\
\dot{q}_{x} & =\frac{x}{\eta \partial^{2} b / \partial \eta^{2}}\left[\frac{\eta}{x} \frac{\partial^{2} b / \partial \eta^{2}}{\partial^{2} c / \partial q_{y}^{2}} \frac{\partial^{2} c}{\partial q_{y} \partial t}-\theta \dot{\omega}\right] \\
\dot{q}_{y} & =\frac{1}{\eta \partial^{2} c / \partial q_{y}^{2}}\left[\dot{\omega}-\frac{\partial^{2} c}{\partial q_{y} \partial t}\right] \\
\dot{q} & =\frac{1}{\eta u^{\prime \prime}} \dot{\omega} \text { and } \dot{p}=\frac{1}{\eta} \dot{\omega} .
\end{aligned}
$$

Since $\dot{\omega}(t)>0$ during such time phases and $\partial^{2} c / \partial q_{y} \partial t<0$ by assumption, 
we conclude from (5.7)-(5.11) that:

$$
\begin{aligned}
& \dot{\eta}>0, \dot{x}<0 \text { and } \dot{q}_{x}<0 \\
& \dot{q}_{y}>0 \\
& \dot{q}<0 \text { and } \dot{p}>0 .
\end{aligned}
$$

The dynamics of the variables during the unconstrained time phases are qualitatively similar to the no technical progress case (see Proposition 1). Benefiting from an increasing competitive advantage with respect to the coal energy production industry, the useful solar energy sector increases its share in the fuel mix, expanding its production rate. The optimality conditions implying that the useful energy price evolves in the same direction as the shadow cost of coal energy when there is no technical progress in the C.U.E industry, the energy price rises over time while the aggregate energy consumption decreases. Such time dynamics has two consequences for the C.U.E sector. The rise of the energy price incites the coal energy industry to boost its energy conversion performance so that $\eta(t)$ increases. On the other hand, the increased competitiveness of solar energy induces a fall of the production rate of C.U.E and thus the industry cuts down its coal consumption rate, inducing in turn a fall of its polluting emissions rate.

\subsubsection{The constrained phase}

We show in appendix A. 3 that:

$$
\begin{aligned}
& \dot{\eta}<0 \text { and } \dot{q}_{x}=\dot{\eta} \bar{x}<0 \\
& \dot{q}>0 \text { and } \dot{p}<0 \\
& \dot{q}_{y}=\dot{q}-\dot{q}_{x}>0 .
\end{aligned}
$$

Contrarily to the no technical progress case where the full shadow cost of coal energy, and thus the useful energy price, remains constant throughout the climate constrained phase, technical advances in renewable energy generation allows for a continuous fall of the shadow cost of coal and the energy price. The C.U.E sector reacts to the declining trend of energy prices 
by reducing its energy conversion performance, $\eta(t)$ decreases. The coal consumption rate being constant at the level $\bar{x}$, the production of C.U.E thus declines. On the other hand the S.U.E sector expands its energy production rate, taking an increasing share in the fuel mix.

Last, since now $\partial b / \partial t=0$, then (5.6) reduces to

$$
\dot{\lambda}_{Z}=\frac{u^{\prime \prime} \eta \dot{q}-\dot{w}}{\eta}<0
$$

The optimal carbon price falls over time like in the original model. The rising competitiveness of solar energy relaxes even more the social cost of the carbon constraint.

\section{Concluding remarks}

We have shown that without technical progress the optimal energy choices of the society may seem paradoxical when the atmospheric $\mathrm{CO}_{2}$ concentration constraint is active since then, amongst the ways allowing to by-pass the constraint, none must be taken. The first one would consist in increasing the efficiency in the fossil fuel energy sector but it is optimal to hold constant the transformation rate of the fossil primary resource into useful energy. The second one would consist in increasing the production of clean renewable energy. But if the clean energy is not exploited before the arrival at the ceiling it must stay non-exploited under the ceiling regime, and if exploited before the arrival and then at an increasing rate, its development must be stopped once the $\mathrm{CO}_{2}$ concentration attains its maximum permitted level.

Non disruptive exogenous smooth technical progress in the fossil fuel sector and in the clean renewable one although both improve the competitiveness of the useful energy production, have however contrasted effects, some of which are even more paradoxical. Technical progress in the fossil fuel sector only results in an increase of the transformation rate of the primary fossil resource into useful energy, hence an increase of the fossil energy production and a decrease of the pollution per unit of useful energy, together with a decrease of the production of clean energy but smaller than the increase of the 
fossil one. Hence under the ceiling regime the energy consumption increases and the share of clean energy in the energy mix continuously declines.

On the contrary the technical progress in only the clean renewable sector results in a continuous decrease of the transformation rate of the fossil resource into useful energy, efficiency decreases once the $\mathrm{CO}_{2}$ concentration hits its ceiling, thus a decrease of the fossil useful energy production and an increase of the $\mathrm{CO}_{2}$ emissions per unit of fossil useful energy. Simultaneously the production of clean energy increases and more than the decrease of the fossil one. Thus under the ceiling regime the useful energy consumption increases and the share of clean energy in the fuel mix is improving.

We have left aside the problem of the distribution of the benefits generated by the technical progress, amongst the final users, the mining sector, the fossil energy transformation sector and the clean energy sector. That would require a complete comparative dynamics of the optimal paths and we doubt that strong results could be obtained under purely qualitative assumptions, the kind of assumptions retained in the present paper. Furthermore to clearly assess the distribution of the net gains it would be necessary to examine the problem of who bear the cost of the research allowing such progress, a problem we leave for further research. 


\section{References}

Amigues J. P. and M. Moreaux, (2013), The atmospheric carbon resilience problem: A theoretical analysis, Resource and Energy Economics, 35(4), 618636.

Amigues J. P. and M. Moreaux, (2016), From primary resources to useful energy: The pollution ceiling efficiency paradox, TSE WP 16-624.

Brookes L. G., (2000), Energy efficiency fallacies revisited, Energy Policy, $28,355-366$.

Carnot S., (1824), Rexions sur la puissance motrice du feu sur les machines propres velopper cette puissance, Bachelier Librairie, Paris.

Chakravorty U., Magn, and M. Moreaux, (2006), A Hotelling model with a ceiling on the stock of pollution, Journal of Economic Dynamics and Control, 30, 2875-2904.

Chakravorty U., Moreaux M., and M. Tidball, (2008). Ordering the extraction of polluting nonrenewable resources, American Economic Review, 98, 1128-1144.

Farzin Y. H., (1996), Optimal pricing of environmental and natural resource use with stock externalities, Journal of Public Economics, vol. 62(1-2), $31-57$.

Farzin Y. H. and O. Tahvonen, (1996), Global carbon cycle and the optimal time path of a carbon tax, Oxford Economic Papers, 48(4), 515-536.

Forster B. A., (1975), Optimal pollution control with a non constant exponential rate of decay, Journal of Environmental Economics and Management, Volume 2, Issue 1, 1-6.

Gaudet G. and P. Lasserre, (1988), On comparing monopoly and com- 
petition in exhaustible resource exploitation, Journal of Environmental Economics and Management, 15(4), 412-418.

Gavankar S. and R. Geyer, (2010), The rebound effect: State of the debate and implications for energy efficiency research, mimeo, Bren School of Environmental Science and Management, University of California, Santa Barbara.

Golosov M., Hassler J., Krusell P. and A. Tsyvinski, (2014), Optimal tax on fossil fuel in general equilibrium, Econometrica, 82(1), 41-88.

Grafton R. Q., Kompass T. and N. G. Long, (2012), Substitution between biofuel and fossil fuels: Is there a green paradox? Journal of Environmental Economics and Management, 64(3), 328-341.

Hanson, D., (1980), Increasing extraction costs and resource prices: Some further results, Bell Journal of Economics, 11(1), 335-345.

Hart R., (2016), Exhaustible resources in the long run, Journal of Economic Dynamics and Control, 71, 1-20.

Hassler J., Krusell P. and C. Olovsson, (2012), Energy-saving technical change, WP NBER 18456.

Heal, G., (1976), The relationship between price and extraction cost for a resource with a backstop technology, Bell Journal of Economics, 7(2), 371378.

Jevons W. S., (1866), The coal question; An inquiry concerning the progress of the Nation, and the probable exhaustion of our coal mines, Chapman and Hall, London.

Khazzoom J. R., (1980), Economic implications for mandated efficiency in standards for households appliances, The Energy Journal, 1(4), 21-40.

Krulce D. L., (1993), Increasing scarcity rents. A sufficient condition, 
Economic Letters, 43, 235-238.

Kmmel R., (2011), The second law of economics, Springer Science and Business Media, Heidelberg.

Marsden B. and G. S. Jones, (2002), Watt's perfect engine. Steam at the age of invention, Columbia University Press.

Mason C. F. and N. Wilmot, (2015), Modeling damages in climate policy models: Temperature-based or Carbon-based?, CESifo WP 5287.

Nordhaus W., (2014), A question of balance: Weighting the options on global warming policies, Yale University Press, New Haven, CT.

Salant S., Eswaran M. and T. Lewis, (1983). The length of optimal extraction programs when depletion affects extraction costs, Journal of Economic Theory, 31, 364-374.

Sorrell S., (2014), Energy substitution, technical change and rebound effects, Energies, 7, 2850-2873.

Smulders S., Tsur Y. and A. Zemel, (2012), Announcing climate policy: Can a green paradox arise without scarcity, Journal of Environmental Economics and Management, 64(3), 364-376.

Stern N., (2007), The economics of climate change: The Stern review, Cambridge University Press, Cambridge UK.

Tahvonen O., (1997), Fossil fuels, stock externalities and backstop technology, Canadian Journal of Economics, 30(4), 855-874.

Tahvonen O. and J. Kuuluvainen, (1991), Optimal growth with renewable resources and pollution, European Economic Review, 35(2-3), 650-661.

Tahvonen O. and S. Salo, (1996), Non convexities in optimal pollution accumulation, Journal of Environmental Economics and Management, 31 
(2), 160-177.

Tahvonen O. and C. Withagen, (1996), Optimality of irreversible pollution accumulation, Journal of Economic Dynamics and Control, vol. 20(910), 1775-1795

Toman M.A. and C. Withagen, (2000), Accumulative pollution, clean technology and policy design, Resource and Energy Economics, 22, 367-384.

Van der Ploeg F. and C. Withagen, (2014), Growth, renewables and the optimal carbon tax, International Economic Review, 55(2), 283-311.

Weitzman M., (2010), What is the 'damages function' for global warming - and what differences might it makes, Climate Change Economics, 1(1), $57-69$

Withagen C., (1994), Pollution and exhaustibility of fossil fuels, Resource and Energy Economics, 16(3), 235-242. 


\section{Appendix}

\section{A.1 Proof that $\lambda_{Z}(t)=0$ if the ceiling is at- tained at an isolated point $t_{Z}$}

The proof is by contradiction. Assume that there exists $t_{Z}>0$, such that $Z\left(t_{Z}\right)=\bar{Z}, Z(t)<\bar{Z}, t \neq t_{Z}$, and $\lambda_{Z}\left(t_{Z}^{-}\right)=\lambda_{Z 0} e^{(\rho+\alpha) t_{Z}^{-}}>0$. Because $Z(t)<\bar{Z}, t \geq t_{Z}$, then by $(3.13), \lambda_{Z}(t)=0, \geq t_{Z}$, hence $\omega\left(t_{Z}^{-}\right)>\omega\left(t_{Z}^{+}\right)$; and because the price path must be time continuous, then:

$$
\lim _{t \uparrow t_{Z}} u^{\prime}\left(\eta(t) x(t)+q_{y}(t)\right)=p\left(t_{Z}\right)=\lim _{t \downarrow t_{Z}} u^{\prime}\left(\eta(t) x(t)+q_{y}(t)\right),
$$

hence, by (3.5):

$$
\eta\left(t_{Z}^{-}\right)=\eta\left(t_{Z}\right)=\eta\left(t_{Z}^{+}\right)
$$

implying together with (3.6) and the above inequality $\omega\left(t_{Z}^{-}\right)>\omega\left(t_{Z}^{+}\right)$, that:

$$
\begin{aligned}
p\left(t_{Z}\right) & =\lim _{t \uparrow t_{Z}} u^{\prime}\left(\eta(t) x(t)+q_{y}(t)\right)=\left[\omega\left(t_{Z}^{-}\right)+b\left(\eta\left(t_{Z}\right)\right)\right] / \eta\left(t_{Z}\right) \\
& >\left[\omega\left(t_{Z}^{+}\right)+b\left(\eta\left(t_{Z}\right)\right)\right] / \eta\left(t_{Z}\right)=\lim _{t \downarrow t_{Z}} u^{\prime}\left(\eta(t) x(t)+q_{y}(t)\right)=p\left(t_{Z}\right),
\end{aligned}
$$

a contradiction.

\section{A.2 Differentiability at $t_{y}$ and $t_{X}$}

Let us first examine the problem of the differentiability of the U.E. price path at the time $t_{y}$ at which begins the S.U.E production and assume that $t_{y} \in\left(0, \underline{t}_{Z}\right) \cup\left(\bar{t}_{Z}, t_{X}\right){ }^{24}$

Consider the f.o.c. (3.6):

$$
p(t) \eta(t)=\omega(t)+b(\eta(t)) .
$$

\footnotetext{
${ }^{24}$ If either $c^{\prime}\left(0^{+}\right) \leq p(0)$ so that $t_{y}=0$, or $c^{\prime}\left(0^{+}\right)=u^{\prime}(\hat{\eta} \bar{x})$, where $\bar{\eta}$ is the constant value of $\eta(t)$ during the phase at the ceiling, so that $t_{y}=\bar{t}_{Z}$, then clearly the price path is time differentiable excepted at times $\underline{t}_{Z}$ and $\bar{t}_{Z}$, and possibly at time $t_{X}$, if $t_{X}<+\infty$.
} 
Time differentiating at the times at which $\dot{p}(t)$ is well defined and taking into account that $p=b^{\prime}$ by (3.5), we obtain:

$$
\dot{p}(t)=\frac{\dot{\omega}(t)}{\eta(t)} .
$$

Since $p(t)$ is continuous then $\eta\left(t_{y}\right)$ is well defined. Next, by (3.11):

$$
\dot{\omega}(t)= \begin{cases}\rho \lambda_{X}(t)+\zeta \rho \lambda_{Z 0} e^{(\rho+\alpha) t} & , t \in\left(0, \underline{t}_{Z}\right) \\ \rho \lambda_{X}(t) & , t \in\left(\bar{t}_{Z}, t_{X}\right) .\end{cases}
$$

Thus whatever the case, $\dot{\omega}\left(t_{y}\right)$ is well defined, hence also $\dot{p}\left(t_{y}\right)$.

However, although the paths of total U.E production, coal extraction, and both C.U.E and S.U.E production are all continuous, only the total U.E production path is differentiable at $t_{y}$.

Since $p(t)$ is differentiable at $t=t_{y}$, then $q(t)$ too is differentiable:

$$
\dot{q}\left(t_{y}\right)=\frac{\dot{p}\left(t_{y}\right)}{u^{\prime \prime}\left(q\left(q\left(t_{y}\right)\right)\right.}<0,
$$

and also $\eta(t)$, since by (3.5):

$$
\dot{\eta}\left(t_{y}\right)=\frac{\dot{p}\left(t_{y}\right)}{b^{\prime \prime}\left(\eta\left(t_{y}\right)\right)}>0 .
$$

Next, from (3.7):

$$
\dot{q}_{y}\left(t_{y}^{+}\right)=\lim _{t \downarrow t_{y}} \dot{q}_{y}(t)=\lim _{t \downarrow t_{y}} \frac{\dot{p}\left(t_{y}\right)}{c^{\prime \prime}\left(q_{y}(t)\right)}=\frac{\dot{p}\left(t_{y}\right)}{c^{\prime \prime}\left(0^{+}\right)}>0,
$$

so that:

$$
\dot{q}_{y}\left(t_{y}^{-}\right)=\lim _{t \uparrow t_{y}} \dot{q}_{y}(t)=0<\lim _{t \downarrow t_{y}} \dot{q}_{y}(t)=\dot{q}_{y}\left(t_{y}^{+}\right),
$$

hence:

$$
\begin{aligned}
& \dot{q}_{x}\left(t_{y}^{-}\right)=\dot{q}\left(t_{y}^{-}\right)>\dot{q}\left(t_{y}\right)-\dot{q}_{y}\left(t_{y}^{+}\right)=\dot{q}_{x}\left(t_{y}^{+}\right) \\
& x\left(t_{y}^{-}\right)=\dot{q}\left(t_{y}^{-}\right) / \eta\left(t_{y}\right)>\dot{q}\left(t_{y}^{+}\right) / \eta\left(t_{y}\right)>\dot{x}\left(t_{y}^{+}\right) .
\end{aligned}
$$


Let us examine now what happens at $t_{X}$ when $t_{X}<\infty$.

From (A.2.2), because $\lambda_{X}\left(t_{X}^{-}\right)=0$, then $\dot{\omega}\left(t_{X}^{-}\right)=0$ so that, from (A.2.1) and $\tilde{\eta}>0$, we obtain:

$$
\dot{p}\left(t_{X}\right)=\frac{\dot{\omega}\left(t_{X}^{-}\right)}{\eta\left(t_{X}^{-}\right)}=\frac{0}{\tilde{\eta}}=0=\dot{p}\left(t_{X}\right) .
$$

Thus the price path is differentiable at $t_{X}$ when $t_{X}<\infty: \dot{p}\left(t_{X}\right)=0$; hence $\dot{q}\left(t_{X}\right)=0$ and also $\dot{q}_{y}\left(t_{X}\right)=\dot{p}\left(t_{X}\right) / c^{\prime \prime}(\tilde{q})=0$, so that $\dot{q}_{x}\left(t_{X}\right)=$ $\dot{q}\left(t_{X}\right)-\dot{q}_{y}\left(t_{X}\right)=0$. Because $\eta\left(t_{X}\right)=\tilde{\eta}>0$ is well defined, then $\dot{x}\left(t_{X}\right)=$ $\dot{q}_{x}\left(t_{X}\right) / \eta\left(t_{X}\right)=0$.

\section{A.3 Optimal dynamics with exogenous techni- cal progress}

We consider first the unconstrained phases and next the constrained one.

\section{A.3.1 Unconstrained phases}

Assume that both energy sources are competitive, then the system of f.o.c.'s (3.5)-(3.7) writes:

$$
\begin{aligned}
u^{\prime}\left(\eta(t) x(t)+q_{y}(t)\right) & =\frac{\partial b(\eta(t), t)}{\partial \eta} \\
u^{\prime}\left(\eta(t) x(t)+q_{y}(t)\right) \eta(t) & =\omega(t)+b(\eta(t), t) \\
u^{\prime}\left(\eta(t) x(t)+q_{y}(t)\right) & =\frac{\partial c\left(q_{y}(t), t\right)}{\partial q_{y}} .
\end{aligned}
$$

Substituting $\partial b / \partial \eta$ for $u^{\prime}$ from (A.3.1) in (A.3.2) then $\eta^{*}(\omega, t)$, the optimal transformation rate as a function of the full marginal user cost of the coal input, $\omega$, and time $t$, appears now as solving:

$$
\frac{\partial b(\eta, t)}{\partial \eta}-\frac{b(\eta, t)}{\eta}=\frac{\omega}{\eta} .
$$


The equation (A.3.4) is, for the technical progress case, the analogue of (3.14) absent any progress.

Time differentiating the set of above conditions yields the following system in matrix form (dropping the time index):

$$
\left[\begin{array}{ccc}
u^{\prime \prime} x-\frac{\partial^{2} b}{\partial \eta^{2}} & u^{\prime \prime} \eta & u^{\prime \prime} \\
u^{\prime \prime} x \eta & u^{\prime \prime} \eta^{2} & u^{\prime \prime} \eta \\
u^{\prime \prime} x & u^{\prime \prime} \eta & u^{\prime \prime}-\frac{\partial^{2} c}{\partial q_{y}^{2}}
\end{array}\right]\left[\begin{array}{c}
\dot{\eta} \\
\dot{x} \\
\dot{q}_{y}
\end{array}\right]=\left[\begin{array}{c}
\frac{\partial^{2} b}{\partial \eta \partial t} \\
\frac{\partial b}{\partial t}+\dot{\omega} \\
\frac{\partial^{2} c}{\partial q_{y} \partial t}
\end{array}\right]
$$

Let $D$ denote the determinant of this system:

$$
D=\eta^{2} u^{\prime \prime} \frac{\partial^{2} b}{\partial \eta^{2}} \frac{\partial^{2} c}{\partial q_{y}^{2}}<0 .
$$

\section{Technical progress in C.U.E production}

Assume that $\partial c / \partial t=0$, hence $\partial^{2} c / \partial q_{y} \partial t=0$. Technical progress happens only in coal energy production. Applying the Cramer rule, we get:

$$
\begin{aligned}
& \dot{\eta}=\frac{1}{D}\left|\begin{array}{ccc}
\frac{\partial^{2} b}{\partial \eta \partial t} & u^{\prime \prime} \eta & u^{\prime \prime} \\
\frac{\partial b}{\partial t}+\dot{\omega} \eta & u^{\prime \prime} \eta^{2} & u^{\prime \prime} \eta \\
0 & u^{\prime \prime} \eta & u^{\prime \prime}-\frac{\partial^{2} c}{\partial q_{y}^{2}}
\end{array}\right| \\
& =\frac{1}{D}\left\{\frac{\partial^{2} b}{\partial \eta \partial t}\left[\left(u^{\prime \prime} \eta\right)^{2}-u^{\prime \prime} \eta^{2} c^{\prime \prime}-\left(u^{\prime \prime} \eta\right)^{2}\right]\right. \\
& \left.-\left(\frac{\partial b}{\partial t}+\dot{\omega}\right)\left[u^{\prime \prime} \eta\left(u^{\prime \prime}-\frac{\partial^{2} c}{\partial q_{y}^{2}}\right)-\left(u^{\prime \prime}\right)^{2} \eta\right]\right\} \\
& =\frac{u^{\prime \prime} \eta \frac{\partial^{2} c}{\partial q_{y}^{2}}}{D}\left[-\frac{\partial^{2} b}{\partial \eta \partial t} \eta+\frac{\partial b}{\partial t}+\dot{\omega}\right] \\
& =\frac{1}{\eta \partial^{2} b / \partial \eta^{2}}\left[\dot{\omega}+\frac{\partial b}{\partial t}-\frac{\partial^{2} b}{\partial \eta \partial t} \eta\right] \text {. }
\end{aligned}
$$




$$
\begin{aligned}
& \dot{x}=\frac{1}{D}\left|\begin{array}{ccc}
u^{\prime \prime} x-\frac{\partial^{2} b}{\partial \eta^{2}} & \frac{\partial^{2} b}{\partial \eta \partial t} & u^{\prime \prime} \\
u^{\prime \prime} x \eta & \frac{\partial b}{\partial t}+\dot{\omega} & u^{\prime \prime} \eta \\
u^{\prime \prime} x & 0 & u^{\prime \prime}-\frac{\partial^{2} c}{\partial q_{y}^{2}}
\end{array}\right| \\
& =\frac{1}{D}\left\{-\frac{\partial^{2} b}{\partial \eta \partial t}\left[\left(u^{\prime \prime}\right)^{2} x \eta-u^{\prime \prime} x \eta \frac{\partial c^{2}}{\partial q_{y}^{2}}-\left(u^{\prime \prime}\right)^{2}\right]\right. \\
& \left.+\left(\dot{\omega}+\frac{\partial b}{\partial t}\right)\left[\left(u^{\prime \prime} x-\frac{\partial^{2} b}{\partial \eta^{2}}\right)\left(u^{\prime \prime}-\frac{\partial^{2} c}{\partial q_{y}^{2}}\right)-\left(u^{\prime \prime}\right)^{2} x\right]\right\} \\
& =\frac{1}{D}\left\{u^{\prime \prime} x \eta \frac{\partial^{2} b}{\partial \eta \partial t} \frac{\partial c^{2}}{\partial q_{y}^{2}}-\left(\dot{\omega}+\frac{\partial b}{\partial t}\right)\left[u^{\prime \prime} x \frac{\partial^{2} c}{\partial q_{y}^{2}}+u^{\prime \prime} \frac{\partial^{2} b}{\partial \eta^{2}}-\frac{\partial^{2} b}{\partial \eta^{2}} \frac{\partial^{2} c}{\partial q_{y}^{2}}\right]\right\} \\
& =\frac{x}{\eta^{2} \partial b^{2} / \partial \eta^{2}}\left\{\eta \frac{\partial^{2} b}{\partial \eta \partial t}-\left(\dot{\omega}+\frac{\partial b}{\partial t}\right)\left[1+\frac{\partial^{2} b}{\partial \eta^{2}}\left(\frac{\partial^{2} c / \partial q_{y}^{2}-u^{\prime \prime}}{u^{\prime \prime} x \partial c^{2} / \partial q_{y}^{2}}\right)\right]\right\} \\
& \dot{q}_{y}=\frac{1}{D}\left|\begin{array}{ccc}
u^{\prime \prime} x-\frac{\partial b}{\partial t} & u^{\prime \prime} \eta & u^{\prime \prime} \\
u^{\prime \prime} x \eta & u^{\prime \prime} \eta^{2} & \frac{\partial b}{\partial t}-\dot{\omega} \\
u^{\prime \prime} x & u^{\prime \prime} \eta & 0
\end{array}\right| \\
& =\frac{1}{D}\left\{\frac{\partial^{2} b}{\partial \eta \partial t}\left[\left(u^{\prime \prime} \eta\right)^{2} x-\left(u^{\prime \prime} \eta\right)^{2} x\right]\right. \\
& \left.-\left(\dot{\omega}+\frac{\partial b}{\partial t}\right)\left[\left(u^{\prime \prime}\right)^{2} x \eta-u^{\prime \prime} \eta \frac{\partial^{2} b}{\partial \eta^{2}}-\left(u^{\prime \prime}\right)^{2} x \eta\right]\right\} \\
& =\frac{1}{\eta \partial^{2} c / \partial q_{y}^{2}}\left(\dot{\omega}+\frac{\partial b}{\partial t}\right) \text {. }
\end{aligned}
$$

Since the f.o.c (3.7) writes equivalently $p=\partial c / \partial q_{y}$,

$$
\dot{p}=\frac{\partial^{2} c}{\partial q_{y}^{2}} \dot{q}_{y} \Longrightarrow \dot{p}=\frac{1}{\eta}\left[\dot{\omega}+\frac{\partial b}{\partial t}\right],
$$

and:

$$
\dot{p}=u^{\prime \prime} \dot{q} \Longrightarrow \dot{q}=\frac{1}{\eta u^{\prime \prime}}\left[\dot{\omega}+\frac{\partial b}{\partial t}\right]
$$

These are the expressions given in the text. 
Technical progress in S.U.E production

Assume that $\partial b / \partial t=0$ hence $\partial^{2} b / \partial \eta \partial t=0$. Technical progress happens only in the S.U.E production sector.Then:

$$
\begin{aligned}
& \dot{\eta}=\frac{1}{D}\left|\begin{array}{ccc}
0 & u^{\prime \prime} \eta & u^{\prime \prime} \\
\dot{\omega} & u^{\prime \prime} \eta^{2} & u^{\prime \prime} \eta \\
\frac{\partial^{2} c}{\partial q_{y} \partial t} & u^{\prime \prime} \eta & u^{\prime \prime}-\frac{\partial^{2} c}{\partial q_{y}^{2}}
\end{array}\right| \\
& =\frac{1}{D}\left\{-\dot{\omega}\left[\left(u^{\prime \prime}\right)^{2} \eta-u^{\prime \prime} \eta \frac{\partial^{2} c}{\partial q_{y}^{2}}-\left(u^{\prime \prime}\right)^{2} \eta\right]\right. \\
& \left.+\frac{\partial^{2} c}{\partial q_{y} \partial t}\left[\left(u^{\prime \prime} \eta\right)^{2}-\left(u^{\prime \prime} \eta\right)^{2}\right]\right\} \\
& =\frac{1}{\eta \partial^{2} b / \partial \eta^{2}} \dot{\omega} \text {. } \\
& \dot{x}=\frac{1}{D}\left|\begin{array}{ccc}
u^{\prime \prime} x-\frac{\partial^{2} b}{\partial \eta^{2}} & 0 & u^{\prime \prime} \\
u^{\prime \prime} x \eta & \dot{\omega} & u^{\prime \prime} \eta \\
u^{\prime \prime} x & \frac{\partial^{2} c}{\partial q_{y} \partial t} & u^{\prime \prime}-\frac{\partial^{2} c}{\partial q_{y}^{2}}
\end{array}\right| \\
& =\frac{1}{D}\left\{\dot{\omega}\left[\left(u^{\prime \prime} x-\frac{\partial^{2} b}{\partial \eta^{2}}\right)\left(u^{\prime \prime}-\frac{\partial^{2} c}{\partial q_{y}^{2}}\right)-\left(u^{\prime \prime}\right)^{2} x\right]\right. \\
& \left.-\frac{\partial^{2} c}{\partial q_{y} \partial t}\left[\left(u^{\prime \prime}\right)^{2} x \eta-u^{\prime \prime} \eta \frac{\partial^{2} b}{\partial \eta^{2}}-\left(u^{\prime \prime}\right)^{2} x \eta\right]\right\} \\
& =\frac{x}{\eta^{2} \partial^{2} c / \partial q_{y}^{2}}\left\{\frac{\eta}{x} \frac{\partial^{2} b / \partial \eta^{2}}{\partial^{2} c / \partial q_{y}^{2}} \frac{\partial^{2} c}{\partial q_{y} \partial t}-\dot{\omega}\left[1+\frac{\partial^{2} b}{\partial \eta^{2}}\left(\frac{u^{\prime \prime}-\partial^{2} c / \partial q_{y}^{2}}{u^{\prime \prime} x \partial^{2} c / \partial q_{y}^{2}}\right)\right]\right\} .
\end{aligned}
$$




$$
\begin{aligned}
& \dot{q}_{x}=\dot{\eta} x+\eta \dot{x} \\
& =\frac{1}{D}\left\{\dot{\omega} u^{\prime \prime} \eta \frac{\partial c^{2}}{\partial q_{y}^{2}} x+u^{\prime \prime} \eta^{2} \frac{\partial^{2} b}{\partial \eta^{2}} \frac{\partial^{2} c}{\partial q_{y} \partial t}\right. \\
& \left.+\eta \dot{\omega}\left[\frac{\partial^{2} b}{\partial \eta^{2}} \frac{\partial^{2} c}{\partial q_{y}^{2}}-u^{\prime \prime} x \frac{\partial^{2} c}{\partial q_{y}^{2}}-u^{\prime \prime} \frac{\partial^{2} b}{\partial \eta^{2}}\right]\right\} \\
& =\frac{1}{u^{\prime \prime} \eta \partial^{2} c / \partial q_{y}^{2}}\left[\dot{\omega}\left(\frac{\partial c^{2}}{\partial q_{y}^{2}}-u^{\prime \prime}\right)+u^{\prime \prime} \eta \frac{\partial^{2} c}{\partial q_{y} \partial t}\right] \text {. } \\
& \dot{q}_{y}=\frac{1}{D}\left|\begin{array}{ccc}
u^{\prime \prime} x-\frac{\partial^{2} b}{\partial \eta^{2}} & u^{\prime \prime} \eta & 0 \\
u^{\prime \prime} x \eta & u^{\prime \prime} \eta^{2} & \dot{\omega} \\
u^{\prime \prime} x & u^{\prime \prime} \eta & \frac{\partial^{2} c}{\partial q_{y} \partial t}
\end{array}\right| \\
& =\frac{1}{D}\left\{-\dot{\omega}\left[\left(u^{\prime \prime}\right)^{2} \eta x-u^{\prime \prime} \eta \frac{\partial^{2} b}{\partial \eta^{2}}-\left(u^{\prime \prime}\right)^{2} x \eta\right]\right. \\
& \left.+\frac{\partial^{2} c}{\partial q_{y} \partial t}\left[\left(u^{\prime \prime} \eta\right)^{2} x-u^{\prime \prime} \eta^{2} \frac{\partial^{2} b}{\partial \eta^{2}}-\left(u^{\prime \prime} \eta\right)^{2} x\right]\right\} \\
& =\frac{1}{\eta \partial^{2} c / \partial q_{y}^{2}}\left[\dot{\omega}-\eta \frac{\partial^{2} c}{\partial q_{y} \partial t}\right] \text {. }
\end{aligned}
$$

Since $\dot{\omega}>0$ during the unconstrained phases and $\partial^{2} c / \partial q_{y} \partial t<0$, it is immediate that $\dot{\eta}>0, \dot{x}<0, \dot{q}_{x}<0$ and $\dot{q}_{y}>0$, as claimed in the text. Furthermore:

$$
\begin{aligned}
p=\frac{\partial b}{\partial \eta} & \Longrightarrow \dot{p}=\dot{\eta} \frac{\partial^{2} b}{\partial \eta^{2}}=\frac{1}{\eta} \dot{\omega}>0 \\
& \Longrightarrow \dot{q}=\frac{1}{u^{\prime \prime}} \dot{p}=\frac{1}{u^{\prime \prime} \eta} \dot{\omega}<0
\end{aligned}
$$




\section{A.3.2 The constrained phase}

Since $x(t)=\bar{x}$, the paths of the coal energy transformation rate and the S.U.E. production rate, $\left(\eta(t), q_{y}(t)\right)$ are solution of:

$$
\begin{aligned}
u^{\prime}\left(\eta(t) \bar{x}+q_{y}(t)\right) & =\frac{\partial b(\eta(t), t)}{\partial \eta} \\
u^{\prime}\left(\eta(t) \bar{x}+q_{y}(t)\right) & =\frac{\partial c\left(q_{y}(t), t\right)}{\partial q_{y}} .
\end{aligned}
$$

Time differentiating yields the following system in matrix form:

$$
\left[\begin{array}{cc}
u^{\prime \prime} \bar{x}-\frac{\partial^{2} b}{\partial \eta^{2}} & u^{\prime \prime} \\
u^{\prime \prime} \bar{x} & u^{\prime \prime}-\frac{\partial^{2} c}{\partial q_{y}^{2}}
\end{array}\right]\left[\begin{array}{c}
\dot{\eta} \\
\dot{q}_{y}
\end{array}\right]=\left[\begin{array}{c}
\frac{\partial^{2} b}{\partial \eta \partial t} \\
\frac{\partial^{2} c}{\partial q_{y} \partial t}
\end{array}\right] .
$$

Let $\Delta$ denote the determinant of this system:

$$
\Delta=\frac{\partial^{2} b}{\partial \eta^{2}} \frac{\partial^{2} c}{\partial q_{y}^{2}}-u^{\prime \prime}\left[\frac{\partial^{2} b}{\partial \eta^{2}}+\bar{x} \frac{\partial^{2} c}{\partial q_{y}^{2}}\right]>0 .
$$

When only the C.U.E production sector benefits from technical advances, we obtain through the Cramer rule:

$$
\begin{aligned}
& \dot{\eta}=\frac{1}{\Delta}\left|\begin{array}{cc}
\frac{\partial^{2} b}{\partial \eta \partial t} & u^{\prime \prime} \\
0 & u^{\prime \prime}-\frac{\partial^{2} c}{\partial q_{y}^{2}}
\end{array}\right| \\
& =\frac{1}{\Delta}\left[u^{\prime \prime}-\frac{\partial^{2} c}{\partial q_{y}^{2}}\right] \frac{\partial^{2} b}{\partial \eta \partial t}>0 \text {; } \\
& \dot{q}_{y}=\frac{1}{\Delta}\left|\begin{array}{cc}
u^{\prime \prime} \bar{x}-\frac{\partial^{2} b}{\partial \eta^{2}} & \frac{\partial^{2} b}{\partial \eta \partial t} \\
u^{\prime \prime} \bar{x} & 0
\end{array}\right| \\
& =-\frac{1}{\Delta} u^{\prime \prime} \bar{x} \frac{\partial^{2} b}{\partial \eta \partial t}<0 \text {. }
\end{aligned}
$$

Then:

$$
\dot{q}=\dot{\eta} \bar{x}+\dot{q}_{y}=-\frac{1}{\Delta} \bar{x} \frac{\partial^{2} c}{\partial q_{y}^{2}} \frac{\partial^{2} b}{\partial \eta \partial t}>0
$$


When only the S.U.E production sector benefits from technical progress, we obtain similarly:

$$
\begin{aligned}
\dot{\eta} & =\frac{1}{\Delta}\left|\begin{array}{cc}
0 & u^{\prime \prime} \\
\frac{\partial^{2} c}{\partial q_{y} \partial t} & u^{\prime \prime}-\frac{\partial^{2} c}{\partial q_{y}^{2}}
\end{array}\right| \\
& =-\frac{1}{\Delta} u^{\prime \prime} \frac{\partial^{2} c}{\partial q_{y} \partial t}<0 ; \\
\dot{q}_{y} & =\frac{1}{\Delta}\left|\begin{array}{cc}
u^{\prime \prime} \bar{x}-\frac{\partial^{2} b}{\partial \eta^{2}} & 0 \\
u^{\prime \prime} \bar{x} & \frac{\partial^{2} c}{\partial q_{y} \partial t}
\end{array}\right| \\
& =\frac{1}{\Delta}\left[u^{\prime \prime} \bar{x}-\frac{\partial^{2} b}{\partial \eta^{2}}\right] \frac{\partial^{2} c}{\partial q_{y} \partial t}>0 .
\end{aligned}
$$

Since $q_{x}=\eta \bar{x}, \dot{q}_{x}=\dot{\eta} \bar{x}<0$ and:

$$
\dot{q}=\dot{\eta} \bar{x}+\dot{q}_{y}=-\frac{1}{\Delta} \frac{\partial^{2} b}{\partial \eta^{2}} \frac{\partial^{2} c}{\partial q_{y} \partial t}>0
$$

We conclude that $\dot{p}=u^{\prime \prime} \dot{q}<0$ in the both cases of a technical progress affecting the C.U.E sector only or the S.U.E sector only. 


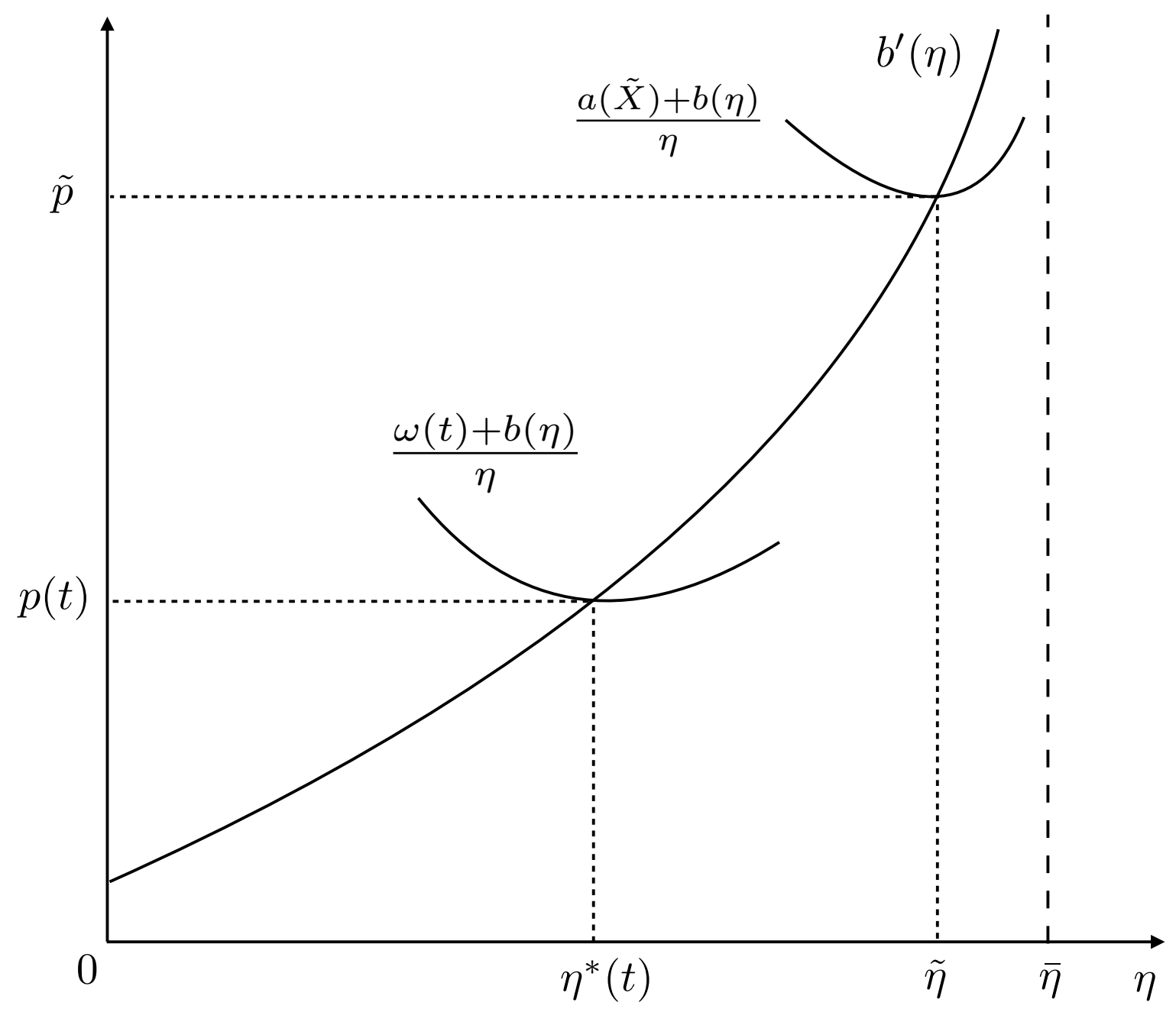

Figure 1: Determination of the Optimal Energy Transformation Rate in the C.U.E Industry and the Un-burnable Coal Stock. 


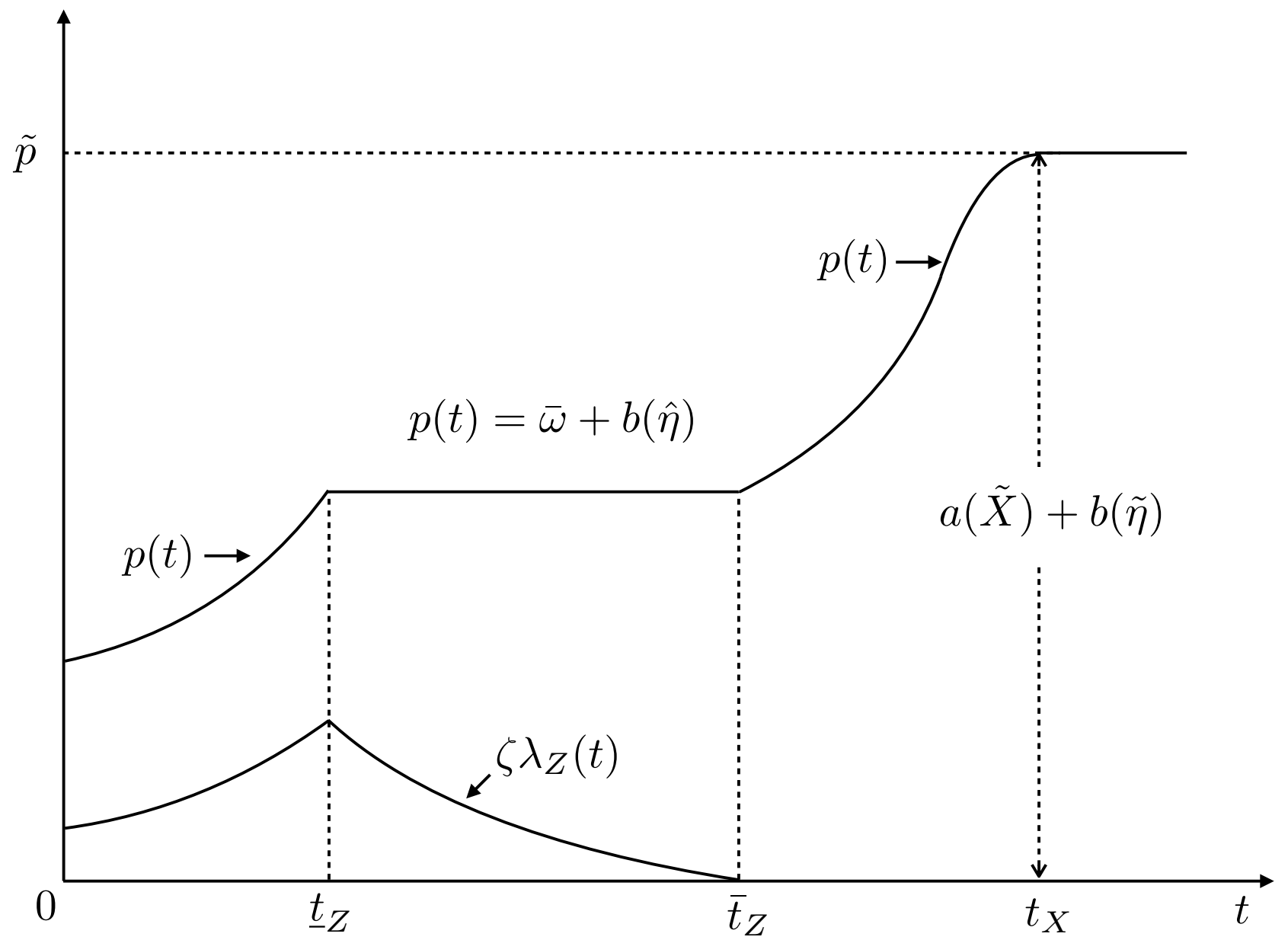

Figure 2: Optimal Price Path of Useful Energy. Case $t_{X}<\infty$.

N.B. $\bar{\omega}=\omega(t)$ and $\hat{\eta} \equiv \eta(t), t \in\left[\underline{t}_{Z}, \bar{t}_{Z}\right]$. 


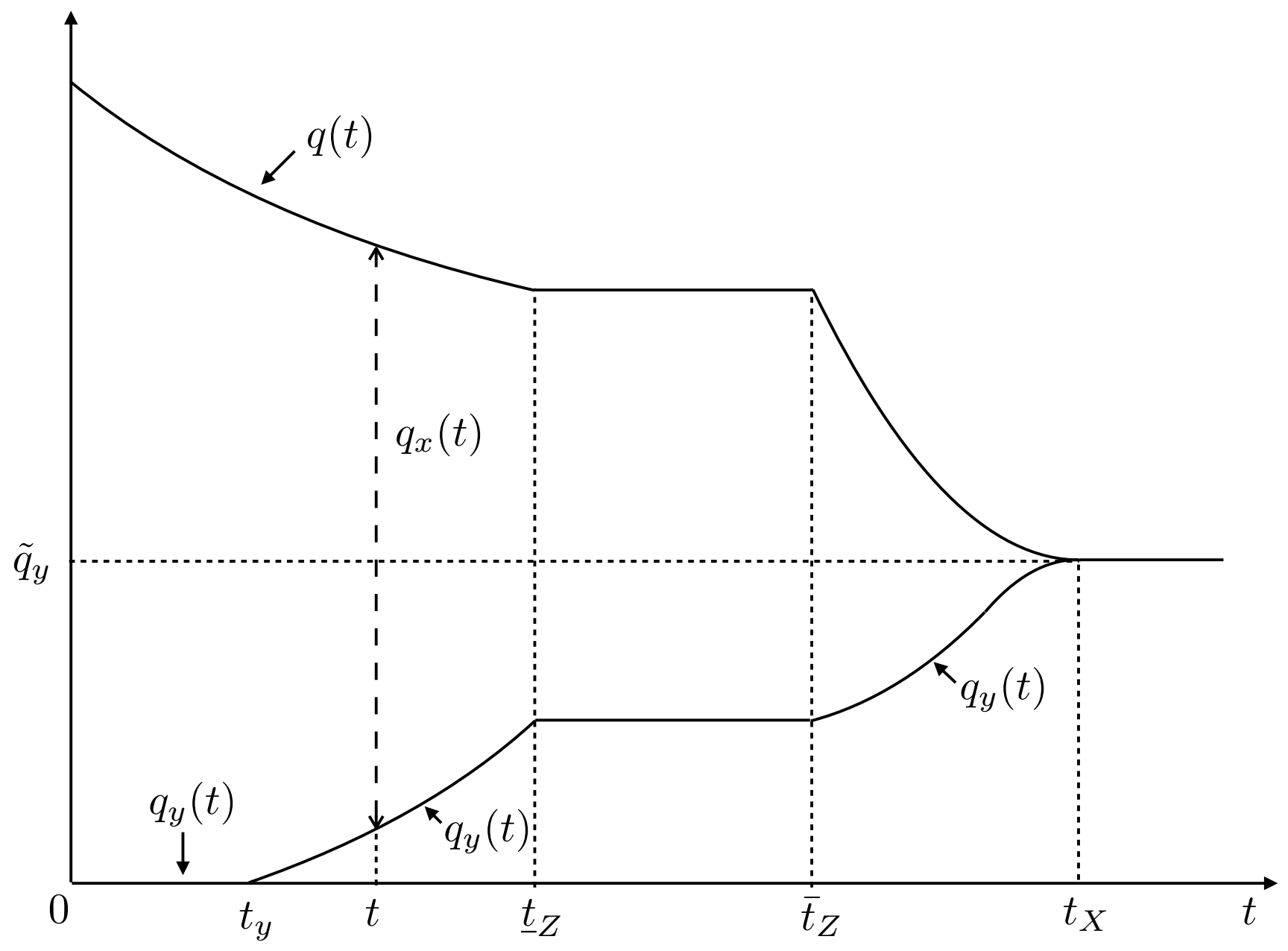

Figure 3: Optimal Paths of Useful Energy Production. Case: $0<$ $t_{y}<\underline{t}_{Z}$ and $t_{X}<\infty$. 


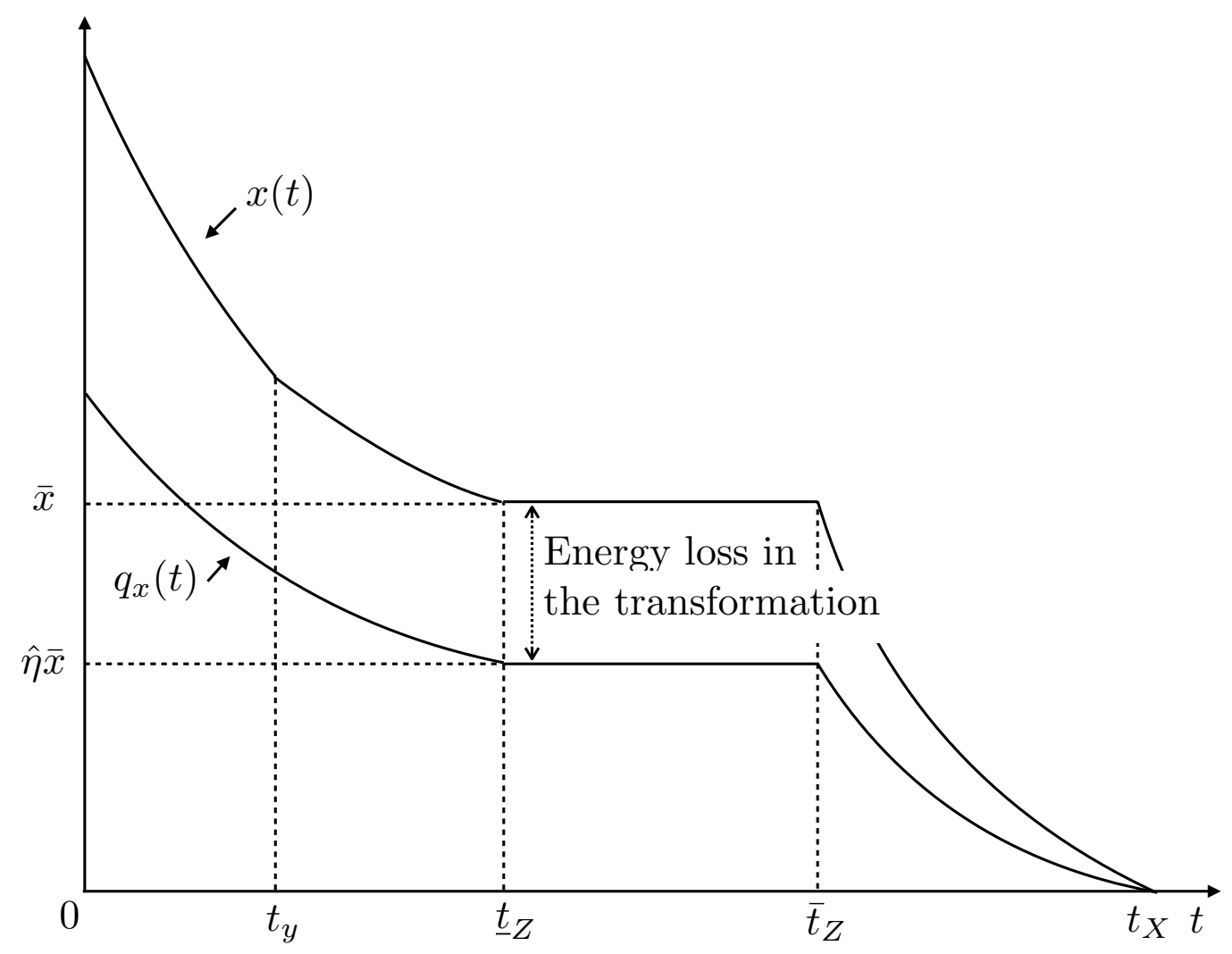

Figure 4: Optimal Paths of Coal Extraction and Coal Useful Energy Production. Case: $0<t_{y}<\underline{t}_{Z}$ and $t_{X}<\infty$. 


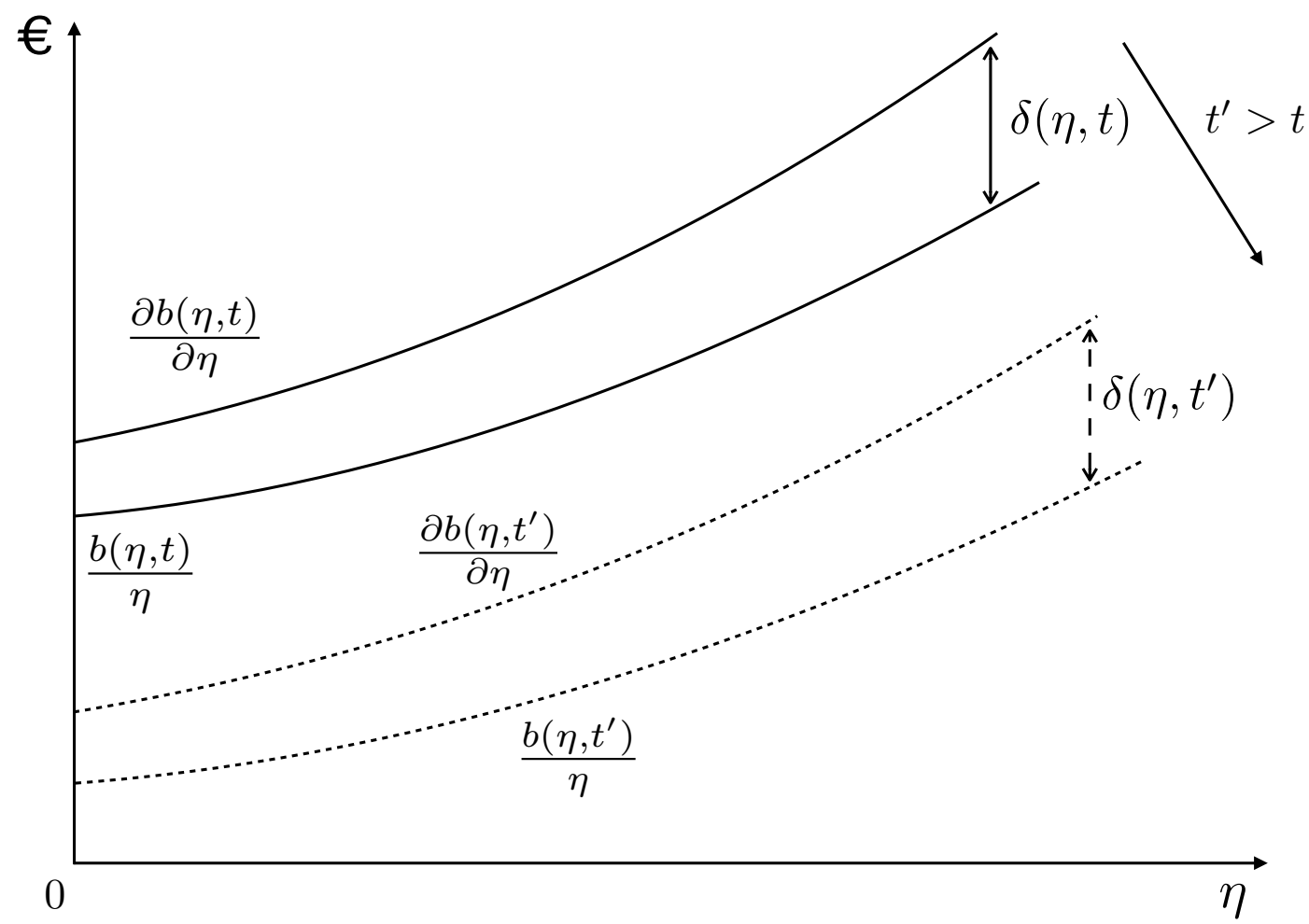

Figure 5: Technical Progress in Coal Useful Energy Production. 